\title{
Hydraulic architecture of trees: main concepts and results
}

\author{
Pierre Cruiziat*, Hervé Cochard and Thierry Améglio \\ U.M.R. PIAF, INRA, Université Blaise Pascal, Site de Crouelle, 234 av. du Brezet, 63039 Clermont-Ferrand Cedex 2, France
}

(Received 10 March 2001; accepted 13 February 2002)

\begin{abstract}
Since about twenty years, hydraulic architecture (h.a.) is, doubtless, the major trend in the domain of plants (and especially trees) water relations. This review encompasses the main concepts and results concerning the hydraulic of architecture of trees. After a short paragraph about the definition of the h.a., the qualitative and quantitative characteristics of the h.a. are presented. This is an occasion to discuss the pipe model from the h.a. point of view. The second part starts with the central concept of embolism and give a review of important experimental results and questions concerning summer and winter embolism. The last part deals with the coupling between hydraulic and stomatal conductances. It discusses the theoretical and experimental relationships between transpiration and leaf water potential during a progressive soil drought, the increase of soil-root resistance and its consequences in term of xylem vulnerability, the factors controlling the daily maximum transpiration and how stomates can prevent "run away embolism". In conclusion different kinds of unsolved questions of h.a., which can be a matter of future investigations, are presented in addition with a classification of trees behaviour under drought conditions. To end, an appendix recalls the notions of water potential, pressure and tension.
\end{abstract}

hydraulic architecture / cohesion-tension theory / summer embolism / winter embolism / drought resistance

Résumé - Architecture hydraulique des arbres : concepts principaux et résultats. Sans aucun doute, depuis une vingtaine d'années, l'architecture hydraulique (a.h.) est devenue une approche majeure dans le domaine des relations plantes-eau (et particulièrement pour les arbres). Cette revue présente les principaux concepts et résultats concernant l'a.h. Après un bref paragraphe sur la définition de l'a.h., les caractéristiques qualitatives et quantitatives définissant l'a.h. sont passées en revue. À cette occasion le « pipe model » est discuté du point de vue de l'a.h. La seconde partie commence avec le concept central d'embolie et continue avec une présentation des principaux résultats et questions touchant l'embolie estivale et l'embolie hivernale. La dernière partie analyse le « couplage » entre les conductances hydraulique et stomatique. Il y est discuté des relations théoriques et expérimentales entre la transpiration et le potentiel hydrique foliaire durant la mise en place d'une sécheresse progressive du sol, de l'augmentation de la résistance sol-racines et de ses conséquences en terme de vulnérabilité du xylème, des facteurs contrôlant la transpiration maximale journalière et de quelle manière les stomates peuvent prévenir l'emballement de l'embolie. La conclusion fait état de différentes questions non résolues, qui pourraient faire l'objet de recherches futures et esquisse une classification du comportement des arbres visà-vis de la sécheresse. Pour finir, un appendice rappelle les notions de potentiel hydrique, de pression et de tension.

architecture hydraulique / théorie de la cohésion-tension / embolie estivale / embolie hivernale / résistance à la sécheresse

\footnotetext{
* Correspondence and reprints

Tel.: +3304736243 66; fax: +3304736244 54; e-mail: cruiziat@ clermont.inra.fr
} 


\section{INTRODUCTION}

During the last decades a new approach of plant and, especially, tree water relations has developed. It is well structured around two main axes: the cohesion-tension theory [37, 38, 92] of the ascent of sap which deals with the physics of the sap movement, and the electrical analogy used for modeling water transport within the tree and in the soil-plant water continuum, using resistances, capacitances, water potentials, flow. Presentation of the cohesion-tension theory and its current controversies have been presented in many recent papers $[26,33,82,113,135]$. The use of an electrical analogy for describing the water transfer through the soil-plant water system is rather old: the idea probably comes from Gradmann [47], but really begins with the article "Water transport as a catenary process" by Van den Honert [143]. It was the main formalism used to deal with water transport in the soil-plantatmosphere continuum from that date until the 1980's, before the hydraulic architecture approach takes over.

It is important to remember that after a period of intense work and debate (from the end of the 19th century to ca. the first half of the 20th), research on the cohesion-tension theory was abandoned with focus instead put on Ohm's law analogy [32]. The resurrection of studies concerning this theory is mainly the result of some pioneers like J.A. Milburn, M.H. Zimmermann and M.T. Tyree.

Hydraulic architecture (h.a.) has made a big improvement in our knowledge by taking into account these two approaches and linking them in a way which allows a much more realistic and comprehensive vision of tree water relationships. Although several papers have been devoted to h.a. $[23,89,127,137]$, we think that there is still a place for a comprehensive and updated introduction intended, as a handbook for frequent reference, to scientists, technicians who are working on tree functioning from one way or another, and students learning tree physiology, but without being specialized in plant water relations. Therefore, to facilitate the understanding, many illustrations have been included in the text where explanations of the figures could be given at greater length than in the legend.

\section{CHARACTERIZATION OF THE HYDRAULIC ARCHITECTURE (H.A.)}

\subsection{What is the hydraulic architecture?}

The h.a. can be considered as a quite well defined region within the vast domain of tree water relations. The expression "hydraulic architecture" was coined by Zimmermann probably in 1977/78, after the first congress on "The architecture of Trees" organized in 1976 in Petersham (MA, USA) by Hallé, Tomlinson and Oldeman, during which he probably got the idea. However, surprisingly, his article of 1978 and, especially, his remarkable book "Xylem Structure and The Ascent of sap" (1983), whose chapter 4 is entitled "Hydraulic Architecture", does not contain any definition of this new expression.

Since that time several definitions have been proposed:

- "h.a. describes the relationship of the hydraulic conductance of the xylem in various parts of a tree and the amount of leaves it must supply" [125];

- "h.a. governs frictional resistance and flow capacity of plant organs" [89];

- "h.a. is the structure of the water conducting system" [127];

- "h.a., that is how hydraulic design of trees influences the movement of water from roots to leaves" (Tyree, 1992, unpublished talk);

- "the set of hydraulic characteristics of the conducting tissue of a plant which qualify and quantify the sap flux from roots to leaves" (Cochard, 1994, unpublished talk).

The soil-root interface can be considered either as a boundary conditions of the plant's hydraulic architecture or as a part of this hydraulic system. As we will see in Section 4, it plays an important role in the tree's water use, in any case.

In fact, h.a. has two different meanings:

(a) A special approach to the functioning of a tree as a hydraulic system. A tree can be considered as a kind of hydraulic system (figure 1). Any such system (dam, irrigation system for crops or houses, human blood vascular system, etc.) is composed of the same basic elements: a driving force, pipes, reservoirs, regulating systems. For trees (and for plants in general) the driving "force" is, most of the time, the transpiration which, as the cohesion-tension theory states, pulls water from the soil to the leaves, creates and maintains a variable gradient of water potential throughout the plant. The energy requirement for transpiration is mainly solar radiation. Thus, when transpiration occurs, the water movement is a passive process along a very complex network of very fine capillaries (vessels and tracheids), which form the xylem conducting system. This conducting (or vascular) system has two kinds of properties: qualitative and quantitative properties.

(b) The result of this approach in terms of maps of the different hydraulic parameters and other measured characteristics, which define the peculiar h.a. of a given tree. It is of course impossible to build such a complete hydraulic map for a large tree; only parts of this map are usually drawn which give some general or species-dependent characteristics of the h.a.

Examples of relevant questions which can be answered through a study of h.a. are: "How do trees without apical control ensure that all branches have more or less equal access to water regardless of their distance from the ground? In times of drought how do trees program which branches are sacrificed first? [127]. What determines the highest level of refilling after embolism? Can we explain some of the differences in life history or phenology of trees or even herbaceous plants (e.g. drought deciduousness) in terms of differences in 
Components of any hydraulic system
Equivalent components of tree like hydraulic system

Solar radiation on leaves

Vascular system

Soil-Root Interface

"Elastic" tissues (living cells) and rigid tissues (dead cells)

Essentially the stomata

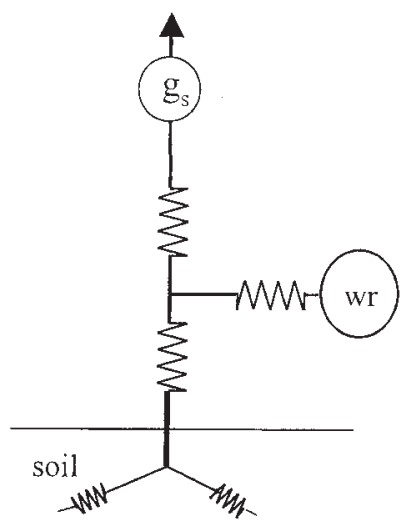

Hydraulic System of tree
Example of non living hydraulic system

A Figure 1. Tree as a hydraulic system; $\mathrm{P}=$ pump; $\mathrm{g}_{\mathrm{s}}=$ stomatal conductance; $\mathrm{wr}=$ water reservoir.

hydraulic architecture? Does hydraulic constraints limit tree height or tree growth?

\subsection{Qualitative characteristics of the hydraulic architecture}

The hydraulic architecture of a tree shows three general qualitative properties: integration, compartmentation and redundancy.

Integration (figure 2, right) means that in most cases (for exceptions see for example [145], the vascular system of a tree seems to form a unique network in which any root is more or less directly connected with any branch and not with a single one. In other words, the vascular system of a tree forms a single, integrated network. Let us represent the tree vascular system by a graph, each leaf and each fine root being

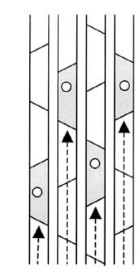

No redundancy

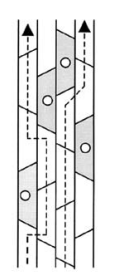

Redundancy

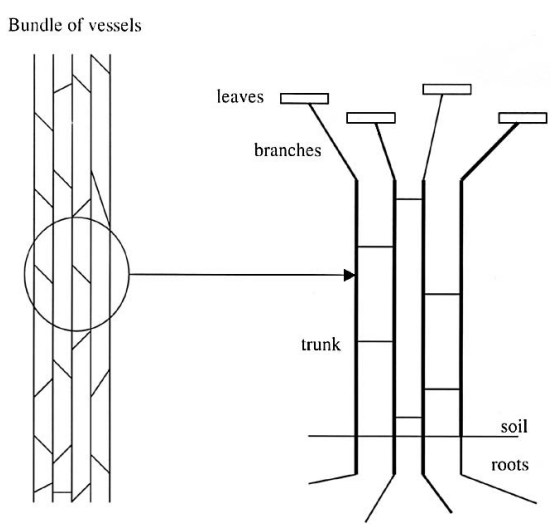

Comparmentation

Integration

Figure 2. Illustration of the three main qualitative characteristics of the hydraulic architecture of a tree: integration, compartmentation and redundancy. 
a different summit. To say that the vascular system forms a unique network means that there is always at least one path between any given summit (between any given root and any given leaf). It is of course impossible to check such an assumption with a large tree. Nevertheless the main idea to keep in mind is the fact that within a tree many possible anatomical pathways, with different resistances, can be used to connect one shoot and one root. It means that water is allowed to flow not only vertically along the large number of parallel pathways formed by files of conducting elements, but also laterally by the pit membrane of these elements which provide countless transversal ways between them. Among the different observations supporting this conclusion, two can be quoted: the dye injection experiments and the split-roots experiments. Roach's work [97] deals with tree injection, i.e. when a liquid is introduced into a plant through a cut or a hole in one of its organs. As Roach said: "The development of plant injection was mainly the indirect result of the attempts of plant physiologists to elucidate the cause of the ascent of sap in trees". Unfortunately the work of Roach is not aimed at tracing the path followed by the transpiration stream. Nevertheless and even if we should be aware of the fact that dyes and water pathways can differ, Roach's work gave extremely interesting and curious information about the connections between different parts of a tree from the leaf level to the whole tree level. As an illustration, here are some quotations from his article:

- "In working with young leaflets, such as those of tomato, a half leaflet is the smallest practical injection unit" (p. 177);

- "If a leaf-stalk injection be carried out on a spur carrying a fruit either the whole fruit or only a single sector of it may be permeated, according to the position of the injected leaf-stalk in regard to the fruit" (p. 183);

- "Experience with apple and other trees has shown that the cut shoot immersed in the liquid must be at least as large as the one to be permeated, otherwise permeation will not be complete" (p. 197);

- "The lower the hole is placed on the branch the greater is the amount of liquid which enters other parts of the tree" (p. 202);

- "There is not a root corresponding to each chief branch and the roots seem to divide quite independently of the division into branches" (p. 207).

The results of Roach are difficult to interpret because they are very dependent on the experimental conditions (time of the year, transpiration and soil water conditions, etc.) on the one hand and the species (distribution of the easiest pathways between a given point, injection point, and the rest of the tree) on the other hand. In split-root experiments [5, 45, 62] part of the roots of a plant is in a dry soil compartment, the rest being in a well-watered soil. Under these conditions, which in fact, reproduce what happens for the root system of a tree in a dry- ing soil, the whole shoot and not just part of it, is supplied with water.

Compartmentation (figure 2, middle) is almost the opposite property of the vascular system. It simply follows from the fact that the conducting system is built up to hundreds of thousands or millions or even more elementary elements, tracheids and vessels. Each element is a unit of conduction, in communication with other elements by very special structures, the pits, which play a major role in protecting the conducting system from entrance of air (see Section 3.4.). There are two main types of conduits: tracheids and vessels. Even if some tracheids can be quite long $(5-10 \mathrm{~mm})$, those of most of our present-day conifers do not exceed 1 or $2 \mathrm{~mm}$. By contrast, vessels, especially in ring porous trees like oaks, can reach several meters, and may even, be as long as the plant (John Sperry, personal communication). However in most cases (there are notable exceptions, like oak species), these conduits are very short in comparison with the total length of the vascular system going from roots to leaves. It forms a kind of small compartment. When air enters the vascular system it invades an element. Such a property is the necessary property complementary to integration because it allows the conducting system to work under a double constraint: to be continuous for water, and discontinuous for air. In fact, conduit length affects water transport in two opposing ways [29, 154]. Increased length reduces the number of wall crossings, therefore increasing the hydraulic conductance of the vascular pathway. However, a countering effect arises, when cavitation occurs, from the fact that a pathway composed of long conduits will suffer a greater total conductance loss for an equivalent pressure gradient. Another aspect that can be linked up with compartmentation is the "hydraulic segmentation" idea of Zimmermann [154] which can be defined "as any structural feature of a plant that confines cavitation to small, distal, expendable organs in favor of larger organs representing years of growth and carbohydrates investment" [127].

Redundancy (figure 2, left) has two meanings in the present context. First of all, it says that in any axis (trunk, branch, twig, petiole), at a given level, several xylem elements are present, like several pipes in parallel. Therefore if one element of a given track is blocked, water can pass along another parallel track. This is very well illustrated by saw cutting experiments [70]. The second meaning has been pointed out by Tyree et al. [133]. It takes into account an additional anatomical fact: in general a track of conducting elements is not alone but is in close lateral contact with other track of vessels or tracheids. In this case redundancy can be defined (in quantitative terms) as the percentage of wall surface in common. Such a design where conduits are not only connected end to end but also through their side walls, shows pathway redundancy. Figure 2 (left) clearly indicates that in this case the same embolism (open circles) does not stop the pathway for water movement. Redundancy is higher in conifers than in vessel-bearing trees. 


\subsection{Quantitative characteristics of hydraulic architecture}

Quantitative characteristics concern the two main elements of the conducting system, namely the resistances and the reservoirs. Several expressions deal with the resistances or the inverse, the conductances. In fact, two main types of quantities are used: conductances $(\mathrm{k})$, where flow rate is expressed per pressure difference, and conductivities (K), where flow rate is expressed per pressure gradient. When either a conductivity or a conductance is expressed per area of some part of the flow path, the $\mathrm{k}$ and $\mathrm{K}$ can be provided with a suffix (ex.: "s" for xylem area, "l" for leaf area, "p" for whole plant leaf area, "r" for root area, "g" for ground area, etc.).

The hydraulic conductance $\mathrm{k}\left(\mathrm{kg} \mathrm{s}^{-1} \mathrm{MPa}^{-1}\right)$ is obtained by the measured flow rate of water (usually with some $\%$ of $\mathrm{KCl}$ or other substance that prevent the presence of bacteria or other microorganisms which tend to block the pits) divided by the pressure difference inducing the flow. Hydraulic conductance is then the reciprocal of resistance. The water can be forced through isolated stem, root or leaf segment by applied pressures, by gravity feed, or drawn by vacuum with similar results, as long as the pressure drop along the plant segment is known. Hydraulic conductance refers to the conductance for the entire plant part under consideration [43].

The hydraulic conductivity $\mathrm{K}_{\mathrm{h}}\left(\mathrm{kg} \mathrm{s}^{-1} \mathrm{MPa}^{-1} \mathrm{~m}\right)$ is the most commonly measured parameter. $\mathrm{K}_{\mathrm{h}}$ is the ratio between water flux $\left(\mathrm{F}, \mathrm{kg} \mathrm{s}^{-1}\right)$ through an excised branch segment and the pressure gradient $\left(\mathrm{dP} / \mathrm{dx}, \mathrm{MPa} \mathrm{m}^{-1}\right.$ ) causing the flow (figure 4). The larger $K_{h}$, the smaller its inverse, the resistance $R . K_{h}$ can also be considered as the coefficient of the Hagen-Poiseuille law which gives the flow $\left(\mathrm{m}^{3} \mathrm{~s}^{-1}\right)$ through a capillary of radius $r$ due to a pressure gradient $\Delta \mathrm{P} / \Delta \mathrm{x}$ along the pipe:

$$
\text { Flow }=\mathrm{dV} / \mathrm{dt}=\left(\rho \mathrm{r}^{4} / 8 \eta\right) /(\Delta \mathrm{P} / \Delta \mathrm{x})=\mathrm{K}_{\mathrm{h}}(\Delta \mathrm{P} / \Delta \mathrm{x})
$$

with $\mathrm{V}=$ volume of water; $\rho=$ the density of water; $\eta=$ coefficient of viscosity of water $\left(\mathrm{kg} \mathrm{m}^{-1} \mathrm{~s}^{-1}\right)$ and $\mathrm{t}=$ time.

Viscosity depends upon solute content (for example, a concentrated sugar solution is quite viscous and slows down the flow considerably). In general, the solute concentration of xylem sap is negligible and does not measurably influence viscosity. Viscosity is also temperature-dependant [1, 25]. It is important to note that flow rate, $\mathrm{dV} / \mathrm{dt}$, is proportional to the fourth power of the capillary diameter. This means that a slight increase in vessel or tracheid diameter causes a considerable increase in conductivity. As an example [154] lets us suppose we have three vessels. Their relative diameters are 1 , 2 and 4 (for example 40, 80 and $160 \mu \mathrm{m}$ ). Under comparable conditions, the flow in the first capillary being 1 , will be 16 in the second and 256 in the third. This tells us that if we want to compare conductivities in different woody axes, we should not compare their respective transverse-sectional vessel area, vessel density or any such measure. We must compare the sums of the fourth powers of their inside vessel diameters (or radii). As a consequence, small vessels carry an insignificant amount of water in comparison with large ones. In the previous example, the smallest capillary would carry $0.4 \%$, the middle one $5.9 \%$ and the large one $93.8 \%$ of the water.

When many capillaries of different diameters, $\mathrm{d}_{\mathrm{i}}$, are present in parallel, like the vessels in the transverse section of a branch, the Poiseuille-Hagen law is written as follows:

$$
\text { Flow }=\mathrm{K}_{\mathrm{h}} \Delta \mathrm{P} / \Delta \mathrm{x} \text { with } \mathrm{K}_{\mathrm{h}}=(\pi \rho / 128 \eta) \sum_{\mathrm{i}=1}^{\mathrm{n}}\left(\mathrm{d}_{\mathrm{i}}^{4}\right) \text {. }
$$

The principle of measurement of the hydraulic conductivity $\mathrm{K}_{\mathrm{h}}$ proceeds from the above equation. The branch segment is submitted to a small water pressure difference $\Delta \mathrm{P}$ which induces a flux. This flux is measured with a suitable device like, for example, a recording balance. Knowing the flux, $\Delta \mathrm{P}$, and the length $\mathrm{L}$ of the sample, $\mathrm{K}_{\mathrm{h}}$ can be calculated. It should be remembered that, although the principle of this method is very simple, its application requires many precautions [107].

According to the Hagen-Poiseuille law, $K_{h}$ should increase if the number $n$ of conduits per unit-branch cross-section or the average conduit diameter increases. However it is important to realize that when measuring $\mathrm{K}_{\mathrm{h}}$ of a branch, one does not refer either to the diameter of the conducting elements or to their number. Therefore, saying that $\mathrm{K}_{\mathrm{h}}$ can be viewed as the coefficient of the Hagen-Poiseuille law does not imply that $\mathrm{K}_{\mathrm{h}}$ is proportional to $\mathrm{r}$ to the fourth power. There is no simple and stable relation between the total cross section of a branch and the composite conducting surface of the tracheids or vessels, which change along the branch. Regression curves of $\mathrm{K}_{\mathrm{h}}$ versus branch diameter are shown in figure 3 [16]. They lead to a relation between $\mathrm{K}_{\mathrm{h}}$ and $\mathrm{S}$ as: $\mathrm{K}_{\mathrm{h}}=$ $\mathrm{S}^{\alpha}$ with $1<\alpha<2$.

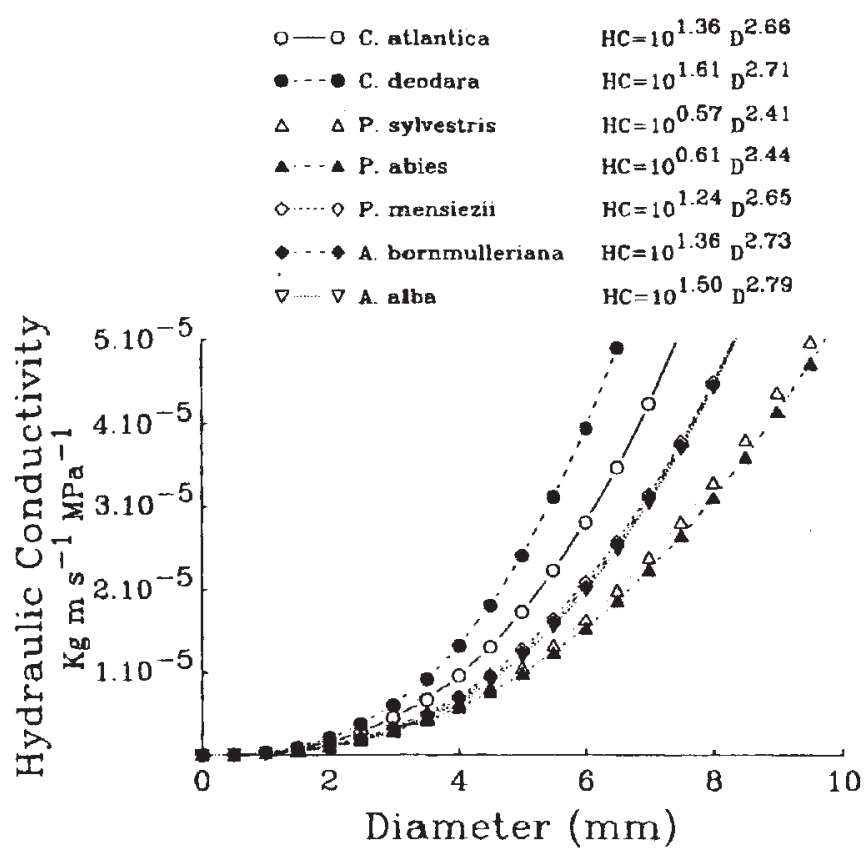

Figure 3. Example of regression between the hydraulic conductivity $\mathrm{K}_{\mathrm{h}}$, and the diameter of the different tree species. Note that all coefficients of regression are $>2$, meaning that $\mathrm{K}_{\mathrm{h}}$ is more than proportional to the branch section (from [16]). 
Whole plant leaf specific conductance $\mathrm{k}_{\mathrm{p}}\left(\mathrm{kg} \mathrm{s}^{-1} \mathrm{MPa}^{-1} \mathrm{~m}^{-2}\right)$ can be calculated by dividing the measured flow rate of water through the stem by the pressure difference and the total leaf surface of the tree. It is a useful parameter because it allows calculation of the soil-to-leaf average pressure drop for a given rate of water.

A)

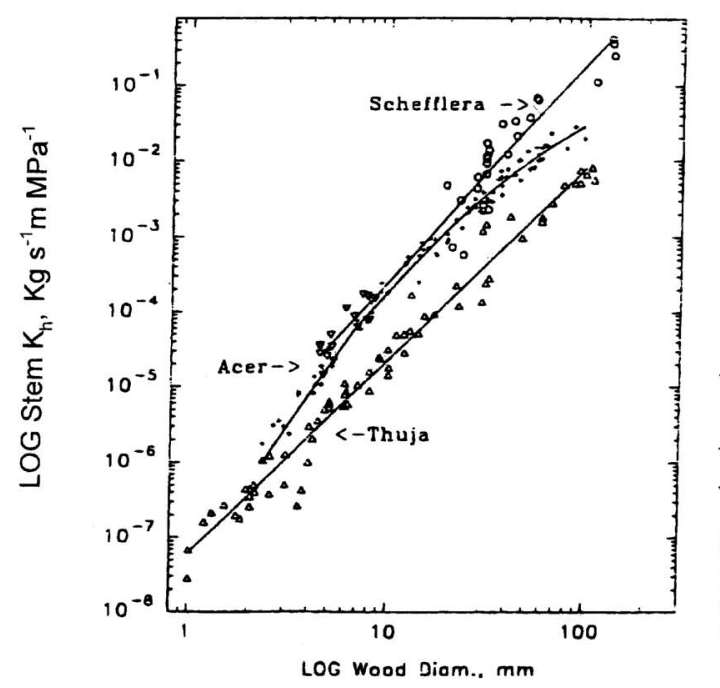

C)

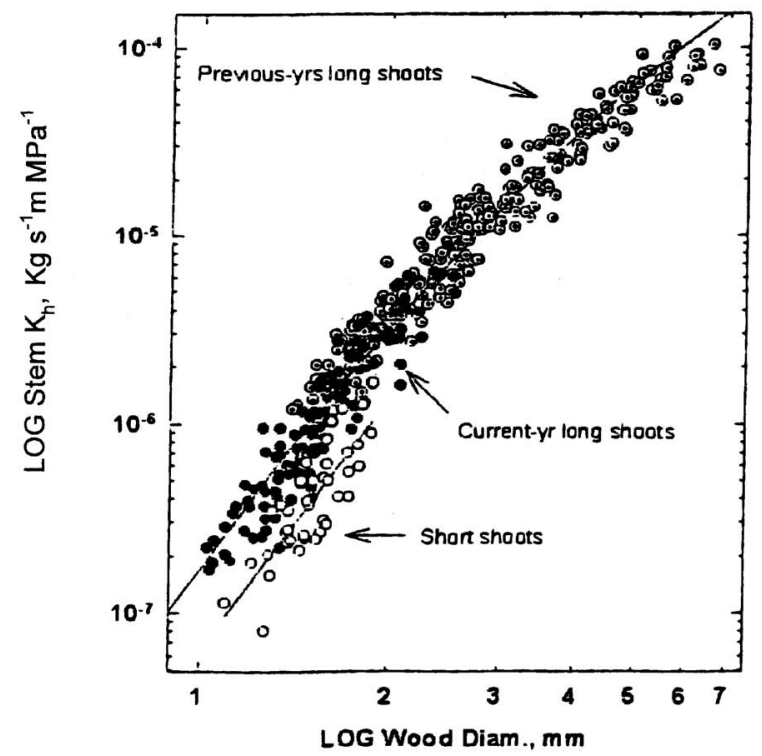

Recently, published results [144, 156], have shown an effect of ionic composition on hydraulic conductance. This effect seems to be small (10\%) in most of the experimented plants species and dose-dependent, but it can be significant in other plants, depending on the ion concentration, $\mathrm{pH}$, and non-polar solvent. In addition, concerning the significance of

B)

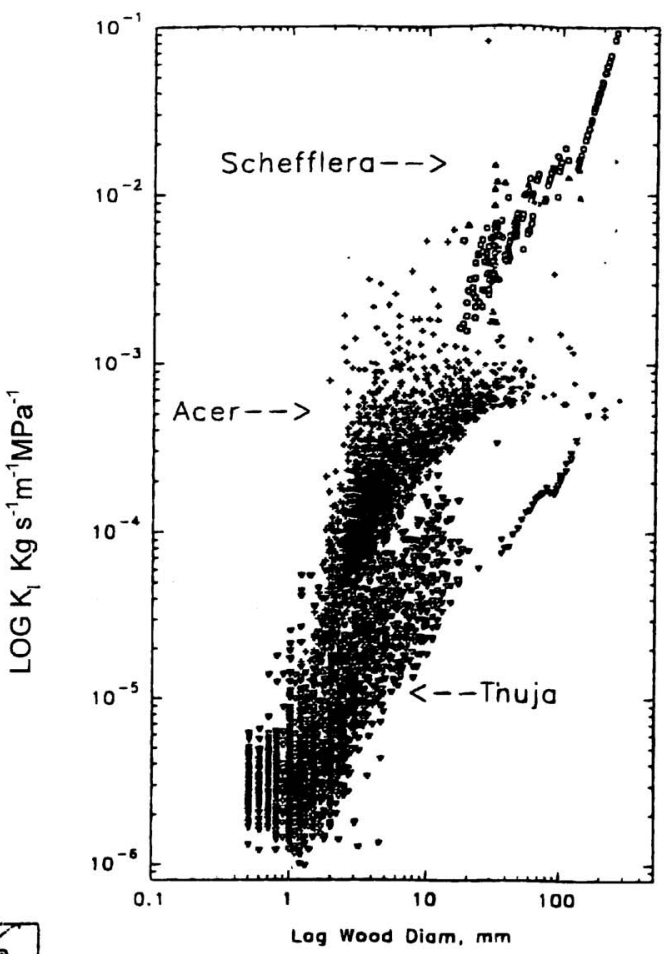

D)

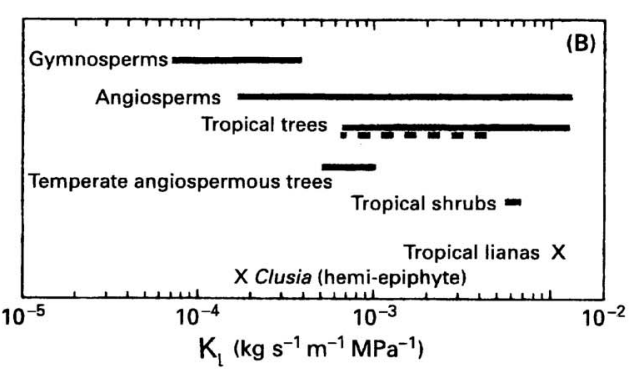

Figure 4. Examples of results of the hydraulic conductivity $\mathrm{K}_{\mathrm{h}}$, and leaf specific conductivity $\mathrm{K}_{\mathrm{l}}$. A: $\log$-log relation between $\mathrm{K}_{\mathrm{h}}($ ordinate) and stem diameter (excluding barck, abscissa) per unit stem lenght for Thuja, $\triangle$; Acer, $\bigcirc$; Schefflera, $\nabla$ (from [128]). B: Same log-log relation for the same species, but for leaf specific conductivity $\mathrm{K}_{\mathrm{l}}$ (from [128]). C: Log-log relation between $\mathrm{K}_{\mathrm{h}}$ (ordinate) and stem diameter (excluding barck, abscissa) for three types of shoots of Fagus sylvestris (from Cochard, unpublished data). D: Ranges of $\mathrm{K}_{1}$ by phylogeny or growth form, read from the bottom axis. Dashed line indicates Ficus spp; "x" indicates a range too short to be represented (from [90]). 
these results in relation to the paradigm of the xylem as a system of inert pipes, they also suggest that measurements of conductance should be made with standard solutions, in term of ionic concentration at least.

Hydraulic resistance $\mathrm{R}_{\mathrm{h}}$, and hydraulic specific resistance $\mathrm{R}_{\mathrm{h}}$. Definition of these two quantities derives from the basic Ohm's equation: flux $=\Delta \Psi / \mathrm{R}_{\mathrm{h}}$. Therefore the units of hydraulic resistances will depend on those expressing the flux (assuming $\Delta \Psi$ is in MPa). For flux expressed in $\mathrm{kg} \mathrm{s}^{-1}, \mathrm{R}_{\mathrm{h}}$ will be in $\mathrm{MPa} \mathrm{kg}^{-1} \mathrm{~s}$ and for flux expressed as a density of flux (the corresponding surface referring to either the sap wood or

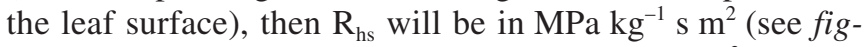
ure $15 \mathrm{C}$ as an example where $\mathrm{kg}$ is replaced by $\mathrm{dm}^{3}$ ).

The specific conductivity $\mathrm{K}_{\mathrm{s}}$ which is given by $\mathrm{K}_{\mathrm{s}}=\mathrm{K}_{\mathrm{h}} / \mathrm{S}$ $\left(\mathrm{kg} \mathrm{s}^{-1} \mathrm{~m}^{-1} \mathrm{MPa}^{-1}\right)$, where $\mathrm{S}$ is the sapwood cross-section and $\mathrm{K}_{\mathrm{h}}$ the hydraulic conductivity expressed in $\mathrm{kg} \mathrm{s}^{-1} \mathrm{~m} \mathrm{MPa}^{-1}$. It is a measure of the "porosity" of the branch segment. As there are many ways to determine this cross-section it is important to specify which one is used, otherwise differences in $\mathrm{K}_{\mathrm{s}}$ cannot be directly compared. Besides, according to its definition, $\mathrm{K}_{\mathrm{s}}$ is proportional to the section of conducting wood of a branch: it means that the Poiseuille-Hagen law is no more valid at the branch level, since along the branch the composition of wood (distribution and number of conducting elements of different diameter) will vary.

The leaf specific conductivity $\mathrm{K}_{1}\left(\mathrm{~kg} \mathrm{~s}^{-1} \mathrm{~m} \mathrm{MPa}^{-1}\right)$ is obtained when $\mathrm{K}_{\mathrm{h}}$ is divided by the leaf area distal to the branch segment $\left(A_{1}, m^{2}\right)$. This is a useful measure of how a branch supplies water to the leaves it bears. Its main use is to calculate the pressure gradients along an axis. Let us suppose that we know the average transpiration flux density $\left(\mathrm{T}, \mathrm{kg} \mathrm{s}^{-1} \mathrm{~m}^{-2}\right)$ from the leaves supplied by the branch segment and that there is no capacitance effect (no change in the water content), then the pressure gradient in the branch segment $(\mathrm{dP} / \mathrm{dx})$ is equals to $T / K_{1}$. So the higher the $K_{1}$, the lower the $d P / d x$ needed to supply the leaves of this axis with water. This conclusion involves two constraints: transpiration per leaf surface is the same, capacitance effects are negligible. A water potential gradient $\Delta \Psi / \Delta \mathrm{x}$ is therefore defined for a given rate of transpiration.

The Hubert value HV. Among the different approaches which have been worked out to get a better understanding of the building of this vascular system, Huber [56] made several measures of the following ratio, named by Zimmermann [154], the "Huber Value" (HV) defined as the sapwood crosssection (or the branch cross-section) divided by the leaf area (or sometimes the leaf dry weight) distal to the branch. It is easy to see that $\mathrm{K}_{1}=\mathrm{HV} \times \mathrm{k}_{\mathrm{s}}$.

Two main series of results (expressed as the ratio of the total cross section, in $\mathrm{mm}^{2}$, of the xylem at a given level, over the total fresh weight of leaves above that level, in $\mathrm{g}$ ), have been obtained by Huber:
- inside a tree this HV is not constant: sun leaves have larger $\mathrm{HV}$ than shade leaves as the apical shoot in comparison with the lateral branches;

- between species adapted to various climates, large differences also exist: Dicots and Conifers from temperate climates of the north hemisphere have HV values around $0.5 \mathrm{~mm}^{2} \mathrm{~g}^{-1}$. For species living in humid or shaded sites, HV values are lower: 0.2 for underground story herbs, 0.02 for Nymphea. On the contrary, plants from dry and sunny countries have HV of 5.9 in average. It is interesting to note that succulents, which have solved the problem of water supply by storage, show very low HV, around 0.10 . We will see hereunder that this approach is close to the pipe model proposed by Shinozaki.

As quoted by Zimmermann [154] this parameter is not very useful for two main reasons. Firstly, the true conducting surface of a trunk or branch is a variable portion of the whole section, which should be determined. Secondly and more important (see above the discussion of the Poiseuille law), the flux of a capillary is proportional to the fourth power of the radius. In other words, through the same cross section of wood and with the same gradient of water potential, $\mathrm{d} \Psi / \mathrm{dx}$, small to very large fluxes can run depending on the distribution of the section of the vessel elements. This is why Zimmermann [153] has proposed the use of the $K_{1}$.

Water-storage capacity. There is considerable evidence that trees undergo seasonal and diurnal fluctuations in water content. These fluctuations can be viewed as water going into and out of storage. Water-storage capacity can be defined in different ways [43]. The relationship between water content and water potential is known as the (hydraulic) capacitance, $\mathrm{C}_{\mathrm{w}}$, of a plant tissue; it is the mass of water $\Delta \mathrm{M}_{\mathrm{w}}$, that can be extracted per $\mathrm{MPa}$ (or bar) change in water potential $(\Delta \Psi)$ of the tissue: $\mathrm{C}_{\mathrm{w}}=\Delta \mathrm{M}_{\mathrm{w}} / \Delta \Psi\left(\mathrm{kg} \mathrm{MPa}^{-1}\right)$. It is also customary to define $\mathrm{C}_{\mathrm{w}}$ for a branch as $\mathrm{C}_{\mathrm{w}}$ per unit tissue volume $\left(\mathrm{kg} \mathrm{MPa}^{-1} \mathrm{~m}^{-3}\right)$ or for leaves, per unit area $\left(\mathrm{kg} \mathrm{MPa}^{-1} \mathrm{~m}^{-2}\right)$. In general these capacitances are difficult to measure, especially because they are not constant but vary with the water potential. Another expression is the water-storage capacity (WSC), which is the quantity of water that can be lost without irreversible wilting. Theoretically, $\mathrm{WSC}=\mathrm{V}(1-\theta)$, where WSC is the storage capacity (e.g. in $\mathrm{kg}$ ), $\mathrm{V}$ is the weight of water when the tissue is at full turgidity and $\theta$ is the critical relative water content leading to irreversible wilting (dimensionless number less than 1). There are practical problems in applying the above equation [43].

According to Zimmermann [154] there are three mechanisms involved in water storage in a tree: capillarity, cavitation and elasticity of the tissues. Cavitation and capillarity effects are the most poorly understood of these. Elasticity of tissue is certainly, for most species, the prevailing mechanism of water storage. Living cells of different parts of the tree have high water content and "elastic" walls. They act as minute water reservoirs having a given capacitance in a 
series-parallel network arrangement. When cells rehydrate, they swell, when they dehydrate, they shrink. The ecophysiological significance of the storage capacity of trees is that it may influence the ability of the tree to continue photosynthesis and, even growth, despite temporary drought conditions.

Some results involving the previous definitions will now be given. Figure $4 A$ [128] shows some examples of $\mathrm{K}_{\mathrm{h}}$ data, and figure $4 B$ [128] the relationship between the logarithm of $\mathrm{K}_{\mathrm{h}}$ and the logarithm of the diameter of the stem for three species. The relation is approximately linear. More important, when the diameter changes by two orders of magnitude ( 1 to $100), K_{h}$ varies by six orders of magnitude. As a consequence, $\mathrm{K}_{\mathrm{h}}$ will change along a branch. The figure also shows large differences between the $K_{h}$ of branches belonging to different species. For example the smallest leaf-bearing branches of Schefflera had $\mathrm{K}_{\mathrm{h}}$ close to those of Acer branches of the same diameter. However, $\mathrm{K}_{\mathrm{h}}$ of larger branches (20 to $30 \mathrm{~mm}$ in diameter) were 3 to 10 times larger in Schefflera than in Acer. Thuja has $\mathrm{K}_{\mathrm{h}} \mathrm{s} 10$ to 20 times smaller than the other two species for branches of the same diameter [128]. Figure $4 C$ shows with Fagus sylvatica another interesting result which demonstrates that there are links between the "botanical" architecture as developed by the French School of Montpellier $[11,54]$ and the hydraulic architecture. The curves express the same type of correlation between the logarithm of $\mathrm{K}_{\mathrm{h}}$ and the logarithm of the diameter for one year shoots. The upper curve summarizes data from long shoots, the lower curve data from short shoots. It is clear that for a given diameter, $\mathrm{K}_{\mathrm{h}}$ of the short shoots tends to be less than $\mathrm{K}_{\mathrm{h}}$ of long shoots. It seems therefore that the conditions undergone by a branch during its development can have hydraulic implications [22]. Similarly considerable differences between the whole plant hydraulic conductance of two co-occurring neotropical rainforest understory shrub species of the genus Piper have been fund [39bis]. These results reflect the conditions where both species are encountered: $P$. trigonum occurs in very wet microsites, whereas, in contrast, $P$ cordulatum is the most abundant in seasonally dry microsites.

Results dealing with root hydraulic conductances are quite rare. An interesting comparison between shoot and root hydraulic conductances in seedling of some tropical tree species shows that, at this stage, shoot and root conductances (and leaf area) all increased exponentially with time [136]. Concerning the roots also, uncertainty appears to exist in the scarce literature regarding the effects of mycorrhizal fungi (ecto and endo-) on the host root hydraulic conductance. So far most studies have been performed in very young seedlings (two to ten months). A recent comparison [83bis] between 2year-old seedlings of Quercus ilex inoculated and non-inoculated with Tuber malanosporum Vitt. showed that root conductance of the inoculated seedlings is 1.27 time greater than those of the non-inoculated seedling. This result has been obtained when the root conductance is scaled by leaf area; in contrast this root hydraulic conductance is lower if reported per unit root area. This example illustrates how important it is to get a correct comprehension of the units used to express the results before trying to explain them.
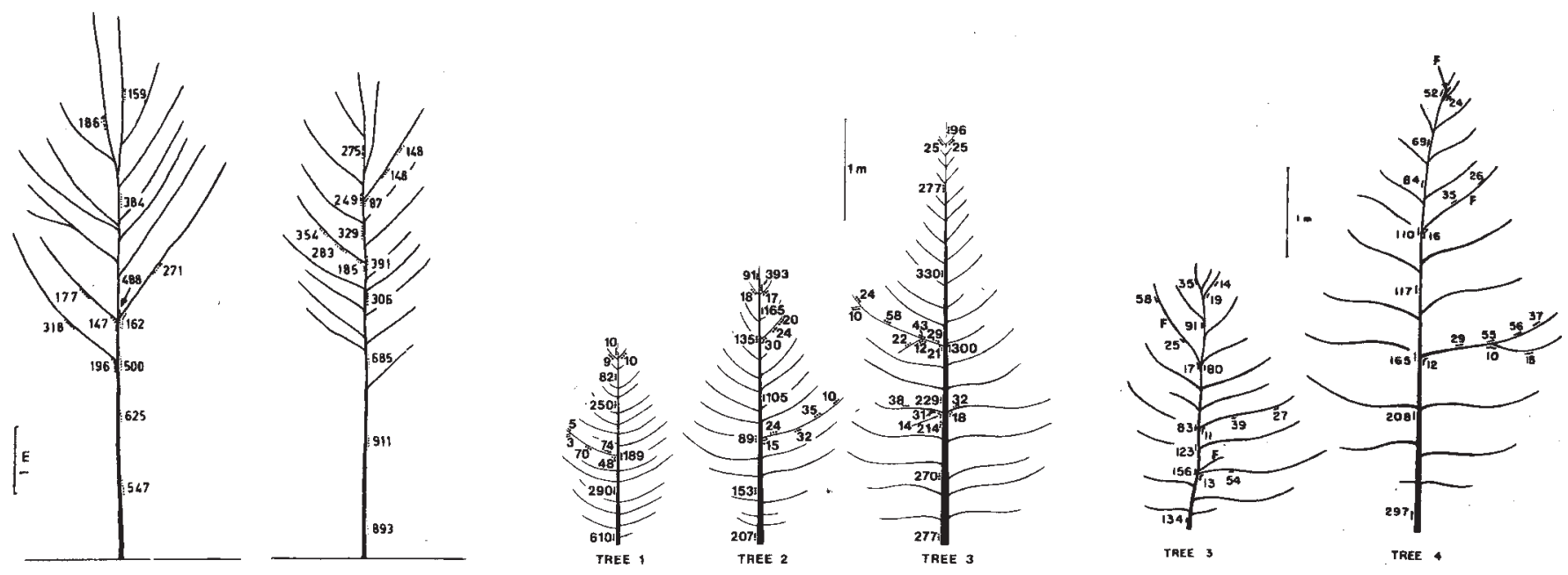

paper birch

(Betula papyfera)

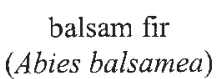

eastern Hemlock

(Tsuga canadensis)

Figure 5. Examples of leaf specific conductivity maps. From left to right: paper birch, Betula papyfera, in microliters per hour, per gram fresh weight of leaves supplied under conditions of gravity gradient, $10.3 \mathrm{kPa} \mathrm{m}^{-1}$ (from [153]); balsam fir, Abies balsamea, same units except per gram of dry weight (from [40]); eastern hemlock, 19-year-old trees, Tsuga canadensis, same units as for balsam fir (from [41]). 
According to its definition, the leaf specific conductivity $\left(\mathrm{K}_{\mathrm{l}}\right)$ depends firstly on the factors controlling the value of $\mathrm{K}_{\mathrm{h}}$ and secondly on the factors that make the leaf surface variable. Therefore it is not surprising that, in figure $5 B$, the variability of $\mathrm{K}_{1}$ is greater than that of $\mathrm{K}_{\mathrm{h}}$. As mentioned above, the principal value of $\mathrm{K}_{1}$ is to allow $\mathrm{dP} / \mathrm{dx}$, (an estimate of the water potential gradient $\Delta \Psi / \Delta \mathrm{x}$, or more precisely, the pressure gradient component of the water potential, see Appendix) along a branch bearing a given foliar area to be calculated. Figure $4 D$ summarizes ranges of values of $\mathrm{K}_{1}$. Hydraulic parameters are now available for many tropical and temperate species $[12,90,138] . \mathrm{K}_{1}$ values ranged over more than two orders of magnitude, from a low of 1.1 (in Clusia) to 171 (in Bauhinia) $\mathrm{kg} \mathrm{s}^{-1} \mathrm{~m}^{-1} \mathrm{MPa}^{-1}$. The conifers had low $\mathrm{K}_{1}$ (values in the range of 1-2) because they have very narrow conduits and diffuse porous trees had about double these values. Not surprisingly, the highest values were in lianas, which "need" wide vessels to promote efficient transport to compensate for narrow stems. Nevertheless, as pointed out by Patiño et al. [90], it is still difficult to be definitive in generalizing interspecific patterns in terms of hydraulic parameters with a data base of only some tens taxa.

Pipe model and hydraulic architecture. The "pipe model theory of plant form" $[102,103]$ views the plant as an assemblage of "unit pipes", each of which supports a unit of leaves. It said that "the amount of leaves existing in and above a certain horizontal stratum in the plant community is directly proportional to the amount of the stems and branches existing in that horizon" [102]. According to the authors, this statement applies at different scales from a simple branch, to an isolated tree and a plant community. Many experimental results support this hypothesis and show that the cross-sectional sapwood area at height $\mathrm{h}$ and the foliage biomass above $\mathrm{h}$, are related through constant ratio. However results also indicate that the ratio may be different for stem and branches and that the transport roots obey a similar relationship [43, 72]. Several models of tree growth use the pipe model $[71,72,84,91$, 141, 142].

In fact the pipe model of Shinozaki can be viewed as a new formulation of one of the Pressler law which said, more than one century ago, that "the area increment of any part of the stem is proportional to the foliage capacity in the upper part of the tree, and therefore, is nearly equal in all parts of the stem, which are free from branches" [10]. From what as been saying above, the pipe model assumption is also very close to the Huber value. As pointed out by Deleuze [36], pipe model, Huber value and allometric relations between leaf surface and stem area are closely related. Nevertheless allometric relations are static and descriptive in nature, like the Huber value, whereas the pipe model theory supposes a conservative relation between structure and functioning.

The pipe model has been useful in predicting canopy leaf mass or leaf area from stem cross section, and is of some value in modeling tree growth, resource allocation and biomechanics [127]. However this model is of little value in understanding tree as hydraulic systems. First it is submitted to the same criticism as the Huber value. As $\mathrm{K}_{1}$ shows, the stem cross section allocated per unit leaf area and the vessel diameter in the stems vary widely within the crown of many trees. Second, it does not consider the varying lengths of transport pathways to different leaves on a tree. This is well explained with the example given by Tyree and Ewers [127]: "Imagine a unit pipe of mass, u, supporting leaf area, s. If the transport distance, $\mathrm{h}$, were doubled with the same leaf area supplied, four unit pipes would be required to maintain the same hydraulic conductance $\mathrm{k}$. If the leaf area were doubled as the transport distance doubled, eight unit pipes would be necessary to equally supply the leaves with water". Underlying explanation is as follows: if neither the pipe units characteristics nor the difference of water potential between soil and leaves change, doubling the distance will then divide the gradient of water potential by two, from $\Delta \mathrm{P} / \Delta \mathrm{x}$ to $\Delta \mathrm{P} / 2 \Delta \mathrm{x}$. To keep the same flux through the system, it is necessary to double the cross area of flux, i.e. to associate two pipe units, doubling then the resistance of the pathway:

$$
\text { Flux }=\mathrm{K}_{\mathrm{h}} \Delta \mathrm{P} / \Delta \mathrm{x}=\mathrm{K}_{\mathrm{h}} \Delta \mathrm{P} / 2 \Delta \mathrm{x}+\mathrm{K}_{\mathrm{h}} \Delta \mathrm{P} / 2 \Delta \mathrm{x} .
$$

As pointed out by the same authors, trees minimize this massive build up of unit pipes, as they age, in two ways. First those that lack secondary growth (e.g. palms) initially are oversupplied with xylem and should attain considerable height before water transport limits. Those with secondary growth, normally produce wider and longer vessels or tracheids at their lower part as they age, which more or less compensate for the increasing distance of transport. As stressed by Jarvis [58] this is also a way trees use to keep the range of water potential of their leaves approximately constant as they grow in height.

Keeping in mind the previous remarks, attempts to build a general and realistic model for the hydrodynamics of plant seem far from being successful. For example, the one published by [147], although based on valuable concepts (allometry laws, theory of resource distribution through a branching network, etc.), contains also several oversimplified assumptions (branching network is supposed to be volume filling, leaf and petiole size are invariant, network of identical tubes of equal length within a segment, constancy of the leaf area distal to a branch, no water capacitance effects, no variable hydraulic conductance, ..., and no indications concerning the boundary conditions in soil and air, etc.), which, in our opinion, ruin the benefit of the use of these concepts. As outlined by Comstock and Sperry [29]: "to model the hydraulic behavior of plants accurately it is necessary to know the conduit length distribution in the water flux pathway associated with species-specific xylem anatomy". Besides, such models have a more problematic defect: they are almost impossible to validate. We think that without a close cooperation between theoreticians and experimenters such general approaches will not have the impact they otherwise could have. 


\subsection{Examples of synthetic data on hydraulic architecture: hydraulic maps}

The first step in building the h.a. of a tree is to measure the hydraulic quantities of different axes and to draw a map, called hydraulic map [137], of their values for different axes. Introduction of the "high pressure flow meter" [132] enabled direct and rapid estimates of the hydraulic resistance of the different elements of the tree structure. Nevertheless few such maps have been published. Figure 5 gives three examples of leaf specific conductivity maps [40, 41, 153]. Several conclusions can be drawn from these data: (i) an important variability of $K_{1}$ exists between different branches of the same tree and differences within the same individual can be greater than between species: for Betula from 911 to 87; for Abies from 3 to 610; for Tsuga, from 10 to 297; (ii) $\mathrm{K}_{1}$ varies along a branch but irregularly. Reasons for that are unclear. It is expected that $\mathrm{K}_{1}$ diminishes with branch diameter but its dependence to the leaf area distribution along the branch can obliterate this trend; (iii) $\mathrm{K}_{1}$ decreases with the order of axe: it is greater in the trunk than in the other branches, and lower at the junctions. In Tsuga, the smallest diameter stems have $\mathrm{K}_{1} \mathrm{~s}$ 30 to 300 times smaller than the largest boles. This means that the pressure gradients, $\mathrm{dP} / \mathrm{dx}$, needed to maintain water flux to transpiring leaves distal to the smallest stem segments, will be 30-300 times steeper than the corresponding gradients at the base of the boles [127], being larger in the main branch than in a secondary branch. Zimmermann [154], spoke about a "bottleneck". This is a general result: hydraulic constrictions at branch junctions are frequently found especially at unequal junctions, i.e. where a small branch arises from a large branch. The basal proximal segment (in the main branch) is more conductive than the junction itself, usually by a factor of 1.1-1.5 [130].

Another example of synthetic data on hydraulic architecture is the negative xylem pressure profile, i.e., the variations of the pressure component of xylem water potential, with height. One speaks also in terms of tension or pressure profiles (see Appendix for the meaning of these different and
A)

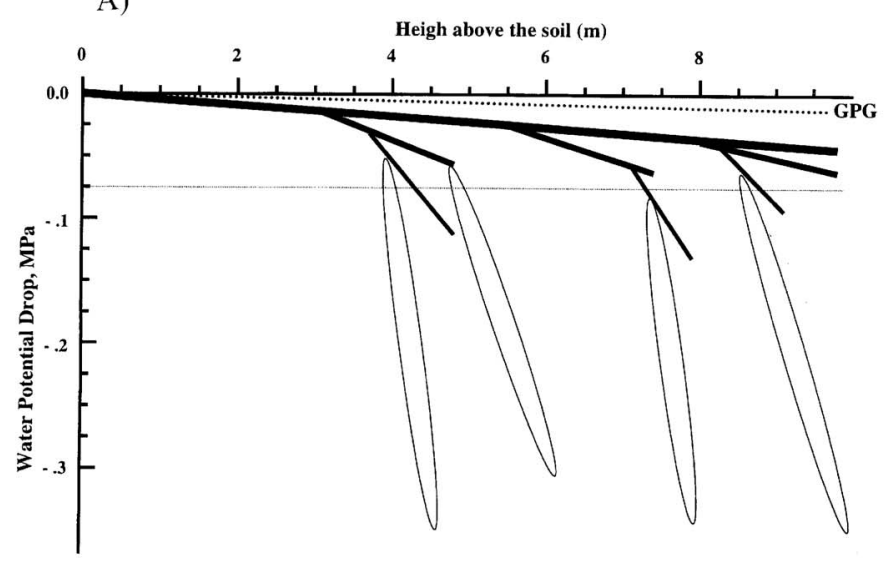

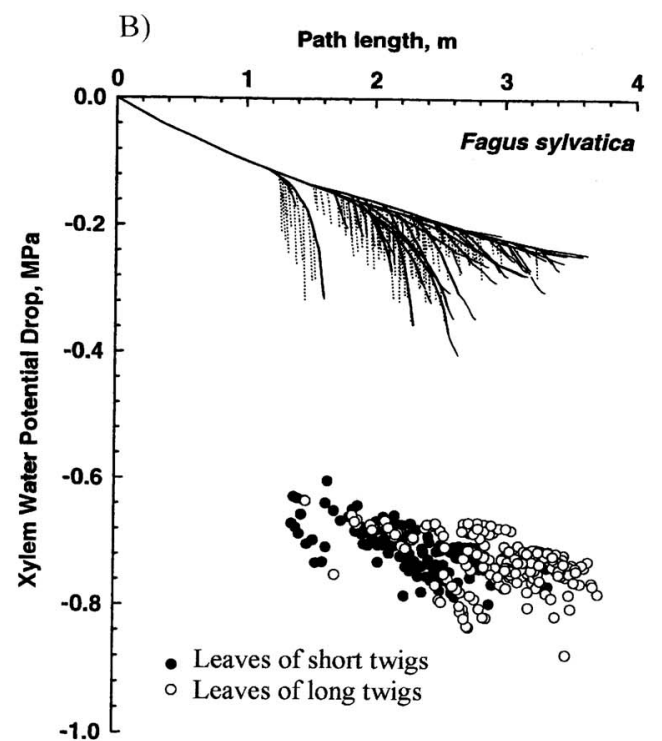

C)

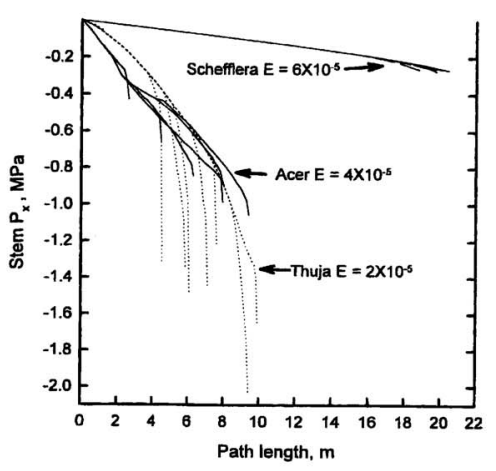

Figure 6. Examples of xylem negative pressure profiles or (gradient) in trees. A: Theoretical profile, showing that most of the gradient of tension is in the leaves; the dotted horizontal line stress the fact that the same tension (here $0.075 \mathrm{MPa}$ ) can be fund at different elevations. GPG line is the tension profile of a stable water column, or gravitational potential gradient. B: Example of such gradient of tension in beech, Fagus sylvatica (from Cochard, unpublished results). C: Other examples of tension gradients for three different species. $\mathrm{E}=$ evaporative flux density $\mathrm{kg}^{-1} \mathrm{~s}^{-1} \mathrm{~m}^{-2}$ (from [128]). 
related expressions). These profiles give the value of the $x y-$ lem sap negative pressure (sap tension) at a given height. Figure $6 A$ represents a theoretical example of such xylem pressure profiles supposing that the xylem pressure in the trunk, at the soil level, is zero. It can be seen that the higher the order of an axis, the steeper is the xylem pressure gradient. For the tree species studied so far, another general fact, emphasized in the drawing, is that the main hydraulic resistance of the trunk-leaf pathway is within the leaf or at least in the petiole-leaf unit $[4,131,132]$. Further research is needed to determine whether or not this fact is a consequence of the resistance of the extra-vascular sap pathway in the leaf. From the functional point of view, if this characteristic hold for all the leaves of a crown, it means that leaves located at the top of the crown will not be disfavored by the longer pathway sap follows to reach them.

Having in mind these theoretical trends of the negative xylem pressure profiles in trees, it is now profitable to look at some measured profiles as presented in figure $6 B$ and $C$. The case of Fagus sylvatica, illustrates the general fact mentioned above: whereas the water potential values for different orders of branches are between -0.08 and $-0.37 \mathrm{MPa}$, those of leaves are between -0.60 and $-0.9 \mathrm{MPa}$. In Thuja occidentalis and Acer saccharum, the difference in xylem pressure disappears for the trunk, but not for the branches. It can also be seen that the negative pressure gradients in Schefflera morototoni barely exceed that required to lift water against the gravitational potential gradient (GPG) or hydrostatic slope to be more simple, (figure 6A). Schefflera morototoni is an interesting extreme with $\mathrm{K}_{1} \mathrm{~s}$ about ten times greater than those of Acer saccharum stems of similar diameter.

Leaf hydraulic resistances have now been measured for a number of tree species but for very few herbaceous species [76]. As said above, most of the resistance in the above ground part of a tree is located within the leaf blade. For example the leaf resistance expressed as a percentage of the total resistance between trunk and leaves is 80 to $90 \%$ for Quercus [132] around 80\% for Juglans regia [131] less than $50 \%$ for Acer saccharum [150]. Measurements of leaf resistance in young apical and old basal branches of a Fraxinus tree have yielded contrasting results [22]. Most of the resistance was indeed located in the leaf blade in the apical shoots, but for older shoots, the resistance was mainly in the axis. This was attributed to the higher node density in older shoots.

Two consequences can be drawn from distribution of resistances in shoots. Firstly, many trees can be compared from the h.a. point of view, to "brooms": many minor shoots with their leaves, forming a set of very high resistances in a parallel arrangement, plugged into a trunk of low resistance. Thuja is a good example of such a "broom" hydraulic architecture: the gradient of xylem pressure is much smaller in the trunk (roughly $0.02 \mathrm{MPa} \mathrm{m}^{-1}$ ) than in the branches, at least ten times larger. Secondly the main factor of variation of the xylem pressure is neither the height, as still often said, nor the length of the pathway from the roots to the leaf. This can be seen in the figure 6A (horizontal dotted line): the same value of xylem pressure is found at several different elevations. What determines the gradient of xylem pressure, $\mathrm{dP} / \mathrm{dx}$ is the hydraulic resistance (inverse of $\mathrm{K}_{\mathrm{h}}$ ) of the water pathway between the trunk and the leaves. Figure 7, from [124], clearly shows this main feature from a model of the h.a. of Thuja: there is no good correlation between the water potential of minor shoots $(<0.8 \mathrm{~mm}$ diameter $)$ and the total path length from soil to shoots (above left diagram) or the vertical height of the shoot (above, right diagram). In contrast, the lower diagrams show close correlation between this water potential and the sum of the leaf specific resistance defined as $\Sigma \mathrm{R}_{\mathrm{i}} \mathrm{A}_{\mathrm{ti}}$ where $R$ is the segment resistance and $A_{t}$ is the total leaf area fed by the segment and the summation is over all segments along the pathway. If all leaves have the same transpiration $\mathrm{T}$ and steady state conditions apply, then the drop in $\Psi$ along the hydraulic path should equal $T \Sigma \mathrm{R}_{\mathrm{i}} \mathrm{A}_{\mathrm{ti}}$. The lower left diagram shows the correlation for all segments $<0.5 \mathrm{~cm}$ diameter. The improved correlation (lower right diagram) demonstrates that most of the hydraulic resistance is encountered in the minor branches. The curvature in the correlation is a consequence of capacitance effects.

An interesting modeling approach has been developed [39] which combines locally measured root hydraulic conductances (from literature), with data on the root architecture (topological and geometrical aspects). For a given distribution of soil water potentials and either a given flux or water potential at the collar, water fluxes along the roots, as well as
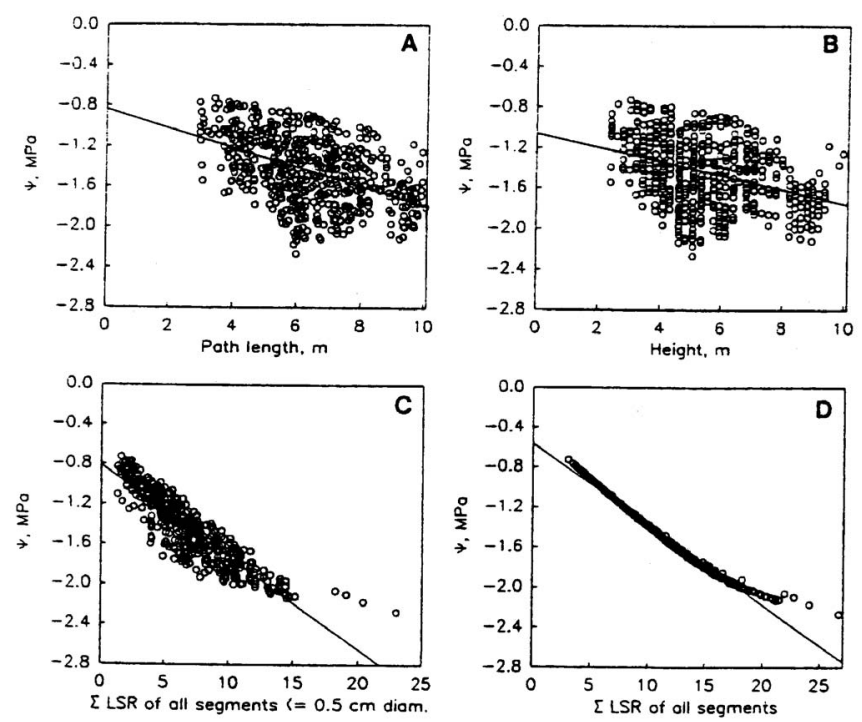

Figure 7. Plots of water potential of minor shoots $(<0.8 \mathrm{~mm}$ in diameter) of Tsuga canadensis versus the total path length from soil to shoot (upper left), versus height (upper right), versus sum of the leaf resistance (lower left) of all branches having a diameter $<0.5 \mathrm{~cm}$, and versus the sum of leaf specific resistance of all the branches (lower right). $\Sigma \mathrm{LSR}$ are $\mathrm{kg}^{-1} \mathrm{~m}^{2} \mathrm{~s} \mathrm{MPa}$. (from [123]). 
the xylem water potentials, can be calculated everywhere in the root system. As expected, water potential distribution along the root system is very dependent of the type of branching (adventitious or taproot for example) and the distribution of the elementary root conductances.

\section{VULNERABILITY AND SEASONAL EMBOLISM}

As stated by the cohesion-tension theory $[118,135]$ water ascends plants in a metastable state of tension, i.e., at negative pressures. The most crucial consequence of this state of tension in the xylem sap is the occurrence of cavitation [19, $81,106,139]$. Cavitation is the abrupt change from liquid water under tension to water vapor. As water is withdrawn from the cavitated conduit, vapor expands to fill the entire lumen. Within hours or less, air diffuses in and the pressure rises to atmospheric $[66,125]$. The conduit then becomes "embolized" (air-blocked). The replacement of water vapor by air is the key point that makes embolism serious since air cannot be dissolved spontaneously in water as can water vapor.

It is now clear that drought can induce cavitation and xylem embolism. This is not the only cause (see Section 3.5) but during summer, this is, by far, the main factor. Therefore, resistance to cavitation is perhaps the most important parameter determining the drought resistance of a tree. A vulnerability curve (VC) is a measure of that "resistance" in particular stem, branch or petiole. It is a relation between the tension of the sap in the xylem conduits and the corresponding degree of embolism as estimated by acoustic detection [79, 96, 100, 126] or, much more frequently, by a hydraulic method [107].

\subsection{The vulnerability curves (VC)}

Figure $8 A$ gives an example of one recent method to determine a vulnerability curve in field (Xyl'em Instrutec Licensed INRA). The principle is simple. A segment of branch collected from the tree under study is first rehydrated to reach complete hydration (full turgidity). Then it is submitted, by means of a collar pressure chamber, to successive increasing steps of air (or nitrogen) pressures. These pressures are positive pressures, above the value of xylem pressure corresponding to full turgidity, which is zero by definition (see Appendix). As a result, mesophyll cells begin to squeeze, thus pushing water from these cells to the xylem vessels and to the protruding end of the branch, where it is collected. The plant sample is now slightly dehydrated. Repeating such small increase of pressure with time will lead to a regular dehydration of the sample and to more and more negative values of its water potential (an intuitive image of this process is the progressive squeezing of a sponge full of water). At each chosen step, the level of embolism is estimated by the measured conductivity $K_{h}$ expressed as a percentage of the maximum $\mathrm{K}_{\mathrm{h}}$ obtained after removal of embolism [17, 107].
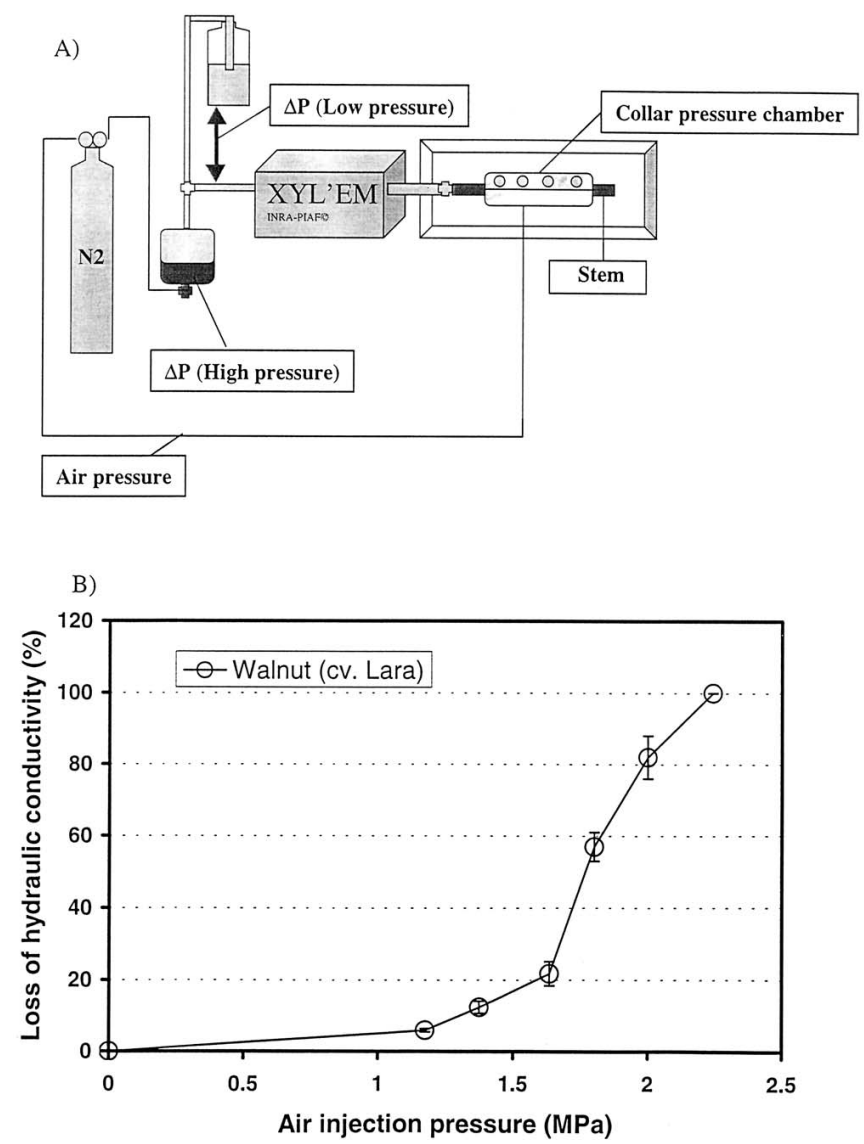

Figure 8. A: Diagram of the apparatus (injection method, one of the possible methods) used to build a vulnerability curve. B: Example of a vulnerability curve, for a branch of walnut tree, Juglans regia (from Ameglio, unpublished result).

In other words a $\mathrm{VC}$, specific to a given axis, is a relation between water potential and the corresponding loss of hydraulic conductivity (figure $8 B$ ). It therefore requires a technique similar to that necessary for the measurement of the hydraulic conductivity.

\subsection{Examples of vulnerability curves}

Figure $9 A$ and $B$ presents some examples of VCs obtained for different trees belonging to Angiosperms and Gymnosperms [127]. As can be seen there are very large differences of vulnerability between species. Among the least vulnerable taxa are Juniperus virginiana, a widely distributed conifer capable of growing on both mesic and xeric sites and Rhizophora mangle, a mangrove growing in saline coastal marshes but whose roots exclude salts from the xylem sap. For these species the water potential for just $20 \%$ loss of conductivity occurs at -5 to $-6 \mathrm{MPa}$ which are very low values. Presently the less vulnerable species have been found in very dry areas. Ceanothus megacarpus, growing in the California chaparral, can resists negative pressures lower than -10 MPa. 
A)

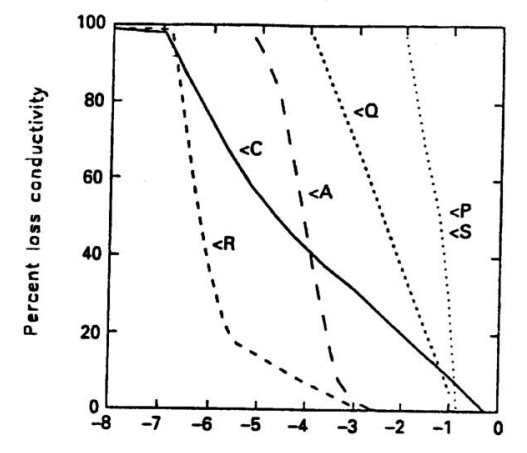

B)

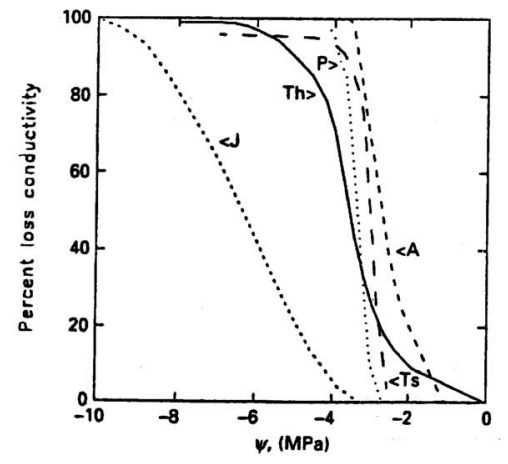

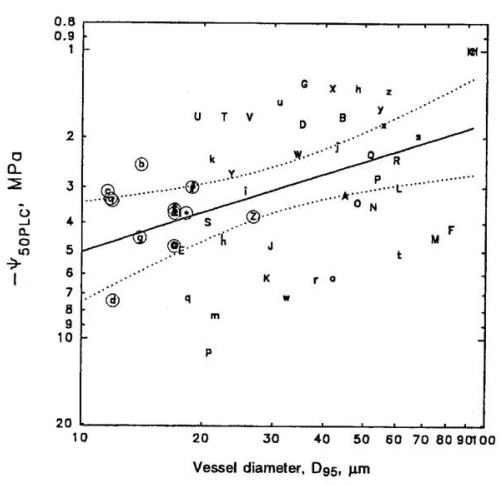

E)

C)

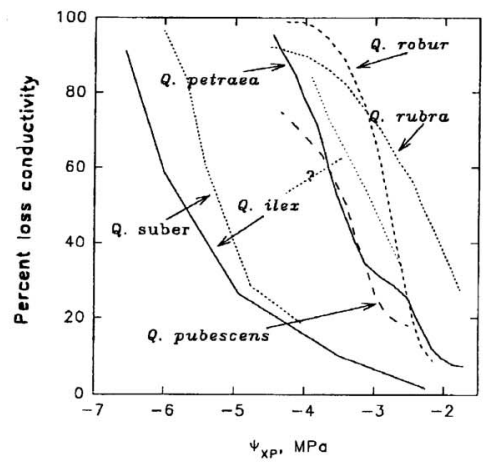

D)

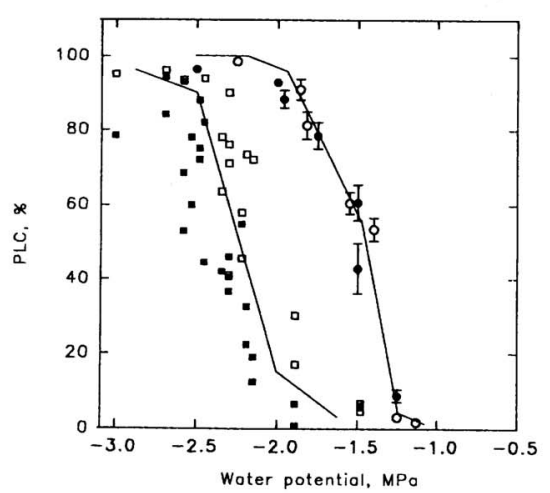

Figure 9. Examples of vulnerability curves. A: Intergeneric examples. Angiosperms. R: Rhizophora mangle; A: Acer saccharum; C: Cassipourea elliptica; Q: Quercus rubra; P: Populus deltoides; S: Schefflera morototoni (from [127]). B: Intergeneric examples. Gymnosperms. J: Juniperus virginiana; Th: Thuja occidentalis; Ts: Tsuga canadensis; A: Abies balsamea; P: Picea rubens (from [127]). C: Intrageneric example. Quercus (from [134]). D: Vulnerability curve of different axes of the same walnut tree, Juglans regia, showing a rare example of vulnerability segmentation (from [131]). E: Log-log plot of xylem tension causing 50\% loss hydraulic conductivity ( 50PLC) and mean diameter of the vessels that account for $95 \%$ of the hydraulic conductance $\left(\mathrm{D}_{95}\right)$. Each symbol is a different species. The solid line is the linear regression of the log-transformed data. The dotted lines are the $99 \%$ confidence interval for the regression (from [133]).
According to Pockman and Sperry [95], Juniperus monosperma did not begin to cavitate until pressures below $-10 \mathrm{MPa}$ and Larrea tridentata was completely embolized at a pressure of $-14 \mathrm{MPa}$ or even less. For Ambrosia dumosa growing at Organ Pipe Cactus National Monument (Arizona), this treshold is around -12 MPa [78]. At the other extreme of vulnerability are Populus deltoïdes Bartr. ex Marsh and Schefflera morototoni which lose $50 \%$ of their hydraulic conductivity at $-1.5 \mathrm{MPa}$. Populus deltoïdes is a temperate mesic species which grows preferentially where water tables are high, and Schefflera morototoni is an evergreen species which grows in rain forests and is an early colonizer of gaps [137].
Some vulnerability curves for roots have been published $[5,67,111]$, which show that the root xylem in woody plants is generally more vulnerable to cavitation than shoots of the same individuals (see references in [95]). Because of their great susceptibility to cavitation, small roots have been called the "Achilles' heel" for water transport within the plant [51]. In this way, embolism may be confined to replaceable roots rather than the stem [95].

An implicit consequence of these VCs is that no strong correlation exists between the diameter of the xylem elements and their vulnerability to summer embolism, as was assumed around the eighties. This has been clearly shown by numerous experimental results, summarized in figure $9 E$ 
[133]: the log-log plot of xylem tension causing $50 \%$ loss of hydraulic conductivity ( $\mathrm{Y}$ axis) and mean diameter the vessels that account for $95 \%$ of the hydraulic conductance (X axis) as a weak correlation (regression accounts for only $21 \%$ of the variation). This statistically significant relation is insufficient to be of predictive value of vulnerability. Figure $9 C$ illustrates the VCs of different species among the genus Quercus. The differences of vulnerability are about as large as between the diverse species of Angiosperms represented figure $9 \mathrm{~A}$. There is a striking correlation between vulnerability curves and general perception of drought tolerance from the silvicultural literature: the arid-zone species $(Q$. ilex and $Q$. suber) are less vulnerable than mesic-zones species (Q. robur and $Q$. petraea). It is worth noting that even 100 percent loss of conductivity of branches may be nonlethal for Quercus species. While most branches died at a soil water potential of $-5 \mathrm{MPa}$, resprouting can occur from roots and some axial buds [134]. Eventually, figure $9 D$ gives the only known example, so far, of what is called "vulnerability segmentation". The idea comes from Zimmermann [154] who spoke of "hydraulic segmentation" as we have seen before. Zimmermann argued that hydraulic segmentation is vital in arborescent monocotyledons, such as palm trees. A palm tree, once formed, can never add new vascular tissue, as dicotyledonous and coniferous trees do. In palms there appears to be substantial hydraulic constriction at the level of the leaf junction [104]. Zimmermann said that this is an essential feature of palm hydraulic architecture to confine embolism to leaves during drought. Leaves are renewable parts, but if the stem is embolized, then the tree may never recover. Tyree and Ewers [127] extended Zimmermann's hypothesis to include "vulnerability segmentation". This exists when the vulnerability of leaves, petioles or minor branches is greater than that of larger branches and the bole. Figure $9 D$ shows such a case for walnut: the VC of stems and petioles gave an order of vulnerabilities of the components of the tree: petioles $>$ current-year shoots $>$ one year-old shoots [131]. When petioles reached $90 \%$ loss of hydraulic conductivity, the leaf water potential $\Psi$ was approximately $-1.9 \mathrm{MPa}$; at the same $\Psi$, the stems had lost only about $15 \%$ of their maximum hydraulic conductivity. This is in contrast to several Quercus, Fraxinus or Populus species where there is no difference in the VC of stems and petioles [18, 20,22]. This study on walnut is the first case showing that drought-induced leaf shedding is preceded by cavitation in petioles before cavitation in stems, due to vulnerability segmentation. However, it is not definitively known that cavitation causes leaf abscission or what the underlying processes are. In the same way more work has to be done to confirm whether or not a causal link exists between the vulnerability to cavitation and branch dieback [98]. The great susceptibility of the small roots to embolism can also be considered as another expression of the vulnerability segmentation.

There is now ample evidence from the literature that VCs vary considerably between species or between organs in a same species. More recent studies have furthermore suggested that VCs can also vary for a same organ according to environmental growth conditions. For instance, shade-grown branches of Fagus sylvatica are more vulnerable than sun-exposed branches [24]. Vulnerability to cavitation is probably an important parameter to consider in order to understand tree phenotypic plasticity.

\subsection{Summer embolism}

During summer, trees undergo drought if the soil dries. Such conditions lead to a decrease of the soil water potential and to a large increase of the hydraulic resistance at the soilroot interface (see Section 4.2). The water potential of leaves will decrease and the xylem sap negative pressure will also decrease. Therefore cavitation and its consequence, embolism will develop and the hydraulic conductivity of the distal parts of tree will decrease. Figure 10A shows, for 30-year-old trees of four oak species [18], the seasonal change in percentage loss of hydraulic conductivity due to embolism in petioles (above) and twigs (below). The open symbols relate to control (irrigated) trees and closed symbols to water stressed trees. It can be seen that there is always, throughout the year, some degree of embolism, even in the well-watered trees. This residual embolism probably comes from vessels with not very well-formed walls or which have been wounded during bad weather or disease.

Another conclusion from these data is that embolism develops during the drought period; but several months of drought are necessary to induce a significant degree of embolism. In fact, efficient mechanisms of defense develop (see below). These results also clearly showed that there is no recovery of embolism after drought has ended. Yang and Tyree [149] presented a model of hydraulic conductivity recovery well confirmed by experimental data. Embolism may dissolved in plant if $\Psi_{\mathrm{x}}$ becomes positive or close to positive for adequate time periods. Embolisms disappear by dissolution of air into the sap surrounding the air bubbles. For air to dissolve from a bubble into liquid sap, the gas in the bubble has to be at a pressure in excess of atmospheric pressure [137]. $\mathrm{P}_{g}$ being the pressure of gas in the bubble and $\mathrm{P}_{1}$ the pressure in the liquid surrounding the bubble $\left(\mathrm{P}_{1}=\Psi_{\mathrm{x}}\right)$ if the difference $\mathrm{P}_{\mathrm{g}}-\mathrm{P}_{1}$ is less than the capillary pressure (originating from the surface tension $\tau$ ), then the gas will dissolve. If this quantity is greater no dissolution will appear. For instance, let us consider an air bubble trapped in a of $60 \mu \mathrm{m}$ vessel diameter. The capillary pressure causes by the surface tension is then equals to ca. $+5 \mathrm{kPa}$ (see Jurin's equation on this page). Therefore, the xylem pressure must be higher (less negative) than $-5 \mathrm{kPa}$ for the bubble to dissolve. Practically, this signifies that, in a non transpiring and well-watered tree, passive embolism can only occur in the root system and up to $50 \mathrm{~cm}$ in the trunk. To dissolve embolism higher in the tree, an active mechanism is required, i.e. a positive root pressure. 
A)

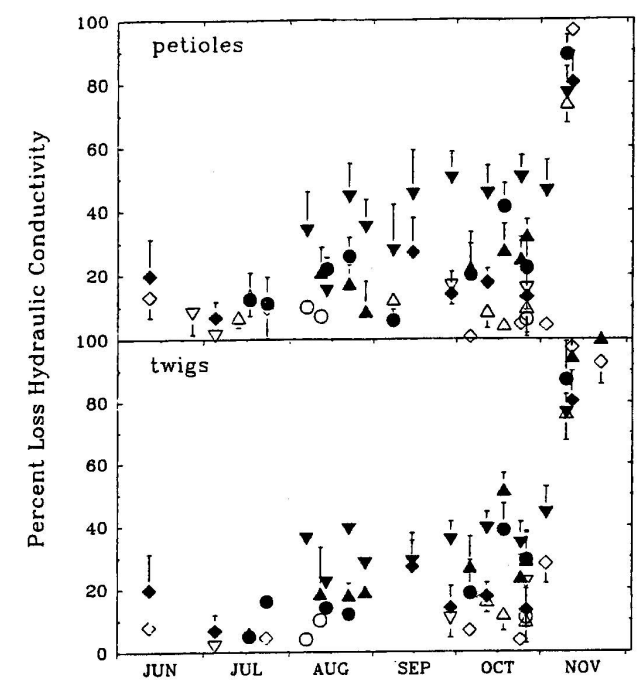

B)
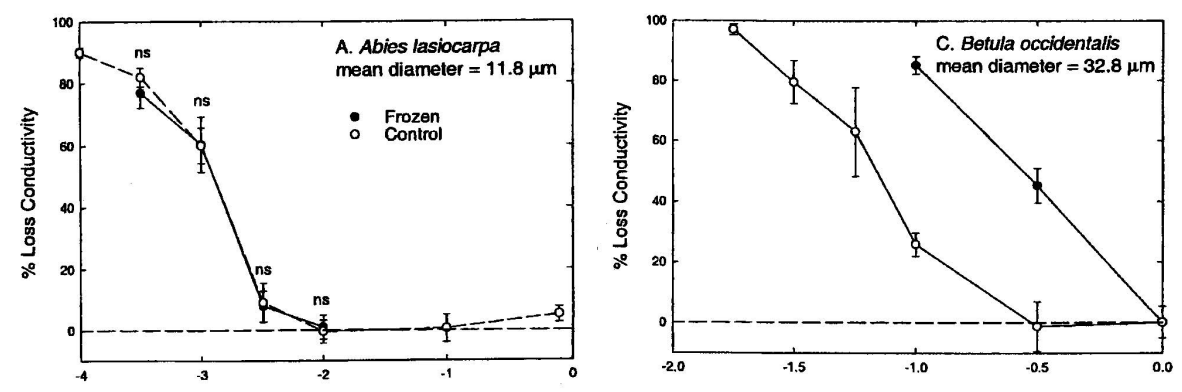

Figure 10. A: Seasonal evolution of xylem embolism in petioles (upper) and one-year old twigs (lower) for both control (open symbols) and water stressed (solide symbols) trees expresseed in \% from completely hydrated twig or petiole specimens. $\boldsymbol{\nabla}$ Quercus robur; Quercus rubra; Quercus petraea; Quercus pubescens (from [18]). B: Vulnerability curves for frozen (solid symbols) and control (open symbols) stems versus xylem pressure for a coniferous (left) and a diffuse-porous deciduous tree (see Section 3.5). Results indicate increasing vulnerability to cavitation by freezing with increasing conduit diameter: freezing causes no additional loss of conductivity relative to water stress controls in Abies contrary to what happens in Betula (from [35]).
However, one must be careful in generalizing, at least for the results and explanations dealing with recovery of embolism. For a long time it was clear that no recovery of embolism can occur during drought. Some theoretical explanations [93] and, especially, recent results [55, 155] suggest that refilling may be more common than previously thought, and that it might occur under negative pressure. More work is needed to get a clear view on this question.

Last but not least, as soon as negative air temperatures occur at the beginning of November, embolism reaches a maximum (hundred percent of loss of hydraulic conductivity). This important result, which has been confirmed by laboratory experiments [15] indicates that another type of embolism, induced by negative air temperatures, can occur in trees. It also shows that the vascular tissue of Quercus is extremely affected by this freezing-induced embolism (see Section 3.5).

\subsection{How to explain the drought-induced embolism? The air-seeding explanation}

While there are many potential causes of xylem cavitation $[92,133]$, the experimental evidence strongly favors the "airseeding" explanation $[31,106,113,154]$. This states that cavitation occurs when air outside a water-filled conduit is aspirated into this xylem element through pores of the pits in the walls (figure 11A). These pores will retain an air-sap meniscus until the difference of pressure between outside and inside (i.e., xylem pressure, $\mathrm{P}_{\mathrm{x}}$ ) across the meniscus, exceeds the capillary forces holding it in place. Outside means either atmosphere, $\mathrm{P}_{\mathrm{a}}$, or an adjacent air-filled conduit, where the pressure is near atmospheric pressure. As Jurin's law (or the capillary equation) states these forces are a function of the pore diameter $\mathrm{d}$, the surface tension of water, $\tau$, and the contact angle between water and the pore wall material $(\alpha)$. The critical pressure difference $\Delta \mathrm{P}_{\text {crit }}$ required to force air through a circular wetted pore can be predicted by this law: 
A)

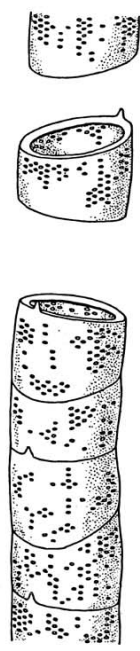

Vessels

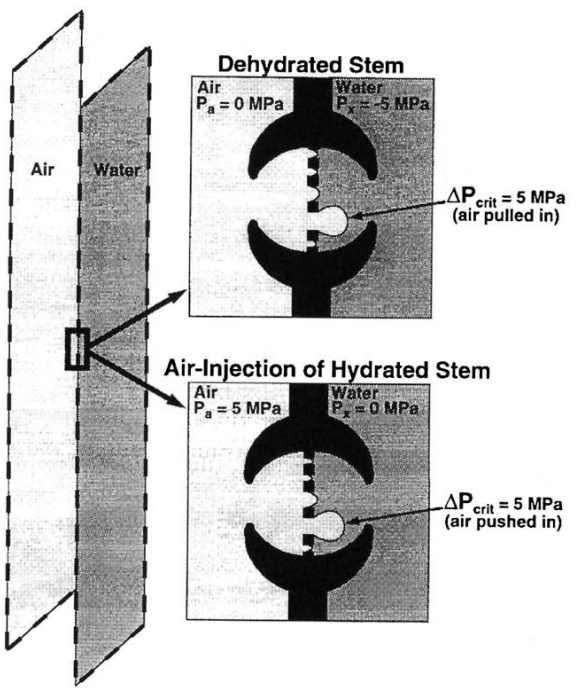

Pit Pair

B)

Tracheids

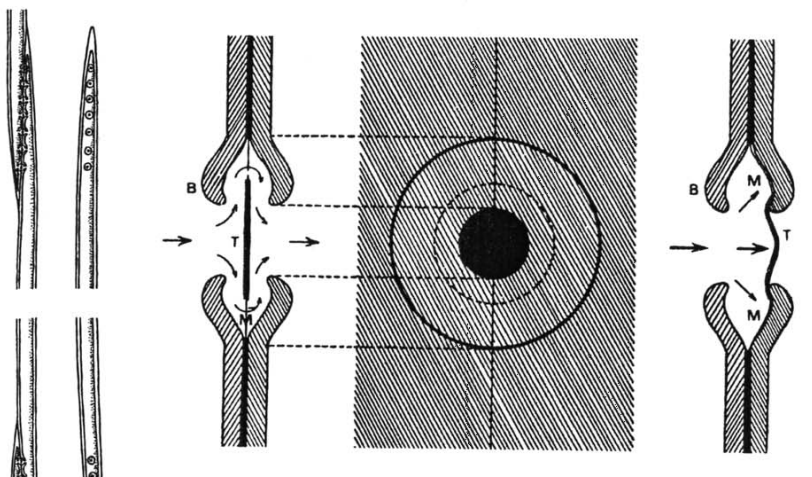

Bordered Pit

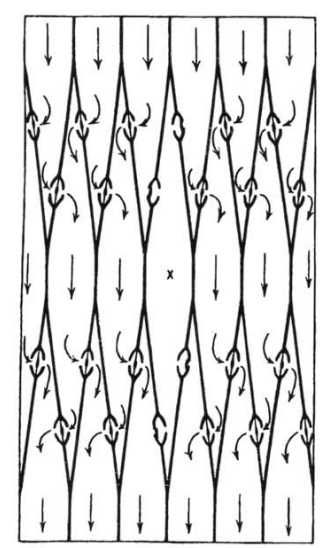

Figure 11. Cavitation in tracheids and vessels. A Left: part of a vessel of oak, large-porous wood (diameter ca. 200-400 $\mu \mathrm{m}$, lenght until some meters) showing vessel elements and pits grouped in small dispersed areas. Right: illustration of the air-seeding explanation. Two adjacent xylem vessels are shown, one being embolized (air filled) the second functional (with sap). Far Right: enlarged view of the intervessel pit structure. The air-seeding explanation states that xylem cavitation in a "dehydrated stem" is initiated by air pulled trough the pit membrane pores. This occurs when the air pressure $\left(\mathrm{P}_{\mathrm{a}}\right.$ usually near zero) minus the xylem pressure $\left(\mathrm{P}_{\mathrm{x}}\right.$, usually negative) across the air-water meniscus at the pore creates a pressure difference $\left(\triangle \mathrm{P}_{\text {crit }}\right)$ sufficient to displace the meniscus. In the example shown, the $\triangle \mathrm{P}_{\text {crit }}$ of $5 \mathrm{MPa}$ is reached when $\mathrm{P}_{\mathrm{x}}=-5 \mathrm{MPa}$. $\mathrm{A}$ corollary of this explanation is that by injection of air in a "hydrated stem", where xylem pressure is atmospheric $(0 \mathrm{MPa}), \triangle \mathrm{P}_{\text {crit }}$ can be achieved by raising the air pressure (to $+5 \mathrm{MPa}$ in this example) (from [113]). B Left: spindle-shaped tracheids (diameter of some $\mu \mathrm{m}$ or tens of $\mu \mathrm{m}$, lenght of some mm) showing small bordered pits. Centre: enlarged views of a bordered pit of a coniferous tracheid; left of centre: pit in section, arrows indicating the path of water from one tracheid to the next; centre: surface view of the same pit; right of centre: section showing the valvelike action of the torus. $\mathrm{T}=$ torus; $\mathrm{M}=$ pit membrane; $\mathrm{B}=$ pit border. Far Right: tangential section of coniferous wood. The tracheid in the center (marked $\mathrm{x}$ ) is embolised. Water flows around it. The negative pressure in the xylem has pulled the pit membranes away from the embolised dead cell to seal it off (from [133]). 


$$
\Delta \mathrm{P}_{\text {crit }}=(4 \tau \cos \alpha) / \mathrm{d}
$$

with $\Delta \mathrm{P}$ in $\mathrm{Pa}, \tau$ in $\mathrm{N} \mathrm{m}^{-1}, \mathrm{~d}$ in $\mathrm{m}$; for water in glass capillaries as well as in the xylem elements of plants $\cos \alpha=1$; $\Delta \mathrm{P}_{\text {crit }}=\mathrm{P}_{\mathrm{a}}-\mathrm{P}_{\mathrm{x}}$.

From this equation it is clear that the bigger the pore, the smaller $\Delta \mathrm{P}_{\text {crit }}$ becomes. Taking $\mathrm{P}_{\mathrm{a}}$ as a constant, the largest pore between two adjacent conduits will then determine the less negative xylem pressure, $\mathrm{P}_{\mathrm{x}}$ which provokes cavitation. An approximation of Jurin's law rewritten in a simplified manner and thus made directly useful for biologists is [154]:

Pore diameter (in $\mu \mathrm{m}) \times$ pressure difference (in atm or bars) $\approx 3$.

For example, if the biggest pore is 0.2 or $0.1 \mathrm{~mm}$ in diameter, then the minimum stable $\mathrm{P}_{\mathrm{x}}$ will be, approximately, -15 or -30 atm, respectively.

Figure $11 \mathrm{~A}$ illustrates this for a typical inter-vessel pit membrane. The diagram shows two adjacent vessels, one filled with air, the other with sap. As water stress increases, $P_{x}$ becomes more negative and $\Delta \mathrm{P}$ increases and eventually reaches the critical value where air is pulled into the conducting element through the pit membrane pore and "seeds" cavitation. As supposed by the air-seeding explanation, only the magnitude of $\Delta \mathrm{P}$ is the triggering factor. Therefore the same result can be achieved either by water stress, as in natural conditions, or by injecting air within a hydrated stem, as in experimental conditions [17].

The air-seeding explanation has been supported by many different experiments [113] and can now be considered as the correct explanation of drought-induced embolism. Its most important consequence is the fact that the vulnerability to embolism is directly determined by the diameter of the pit pores and not by the diameter of the conduits. This could be a useful indication for estimating a priori the degree of safety of a conducting system in regard to vulnerability. However, difficulties still remain as to which is the correct pore diameter to take into account. Most of the time, pit pore diameters are measured using electron microscopy techniques, under relaxed conditions. However under natural conditions, as the pit membrane is subjected to large pressure differences prior to air seeding, it is strongly suspected to be stretched (Sperry, personal communication). Therefore, the exact diameter of the pores can be very different in the relaxed state vs the stretched state, depending on the mechanical properties of the pit membrane.

In conifers where a torus is present in the pit of tracheids (figure $11 B, \mathrm{~T}$ ), the situation is different. When a tracheid embolizes, the pit membrane is deflected against the pit chamber wall and the torus covers the pit aperture (figure $11 \mathrm{~B}$, right). However, this sealing action of the torus is not perfect and air is apparently still able to pass through this torus-blocked pit wall. The problem is to find which way air uses. In the species studied by Sperry and Tyree [109], Abies Balsamea (L.) Mill., Picea rubens Sarg. and Juniperus virginiana (L.), when air enters, it probably does not happen through the torus which appears to be without pores and forms a tight seal over the aperture. Air should then pass through the deflected pit membrane. Besides, the porosity of the pit membrane that supports the torus (the margo, M) is too large to prevent air entering at $\mathrm{P}$ greater than $0.1 \mathrm{MPa}$ in most cases. It therefore could not account for the observed embolism-inducing pressures, which are much less negative. The conclusion of the authors is that the air-seeding pressure is not directly a function of pore size but of membrane flexibility, because the seeding may occur when the torus is displaced from its normal sealing position over the pit aperture. In other words, it can be supposed that the displacement of the pit membrane reduces the size of its pores.

\subsection{Winter embolism}

During winter, freeze-thaw events can induce embolism and reduce the hydraulic conductivity of temperate woody plants $[15,110]$. The seasonal development of embolism in the xylem conduits of Quercus petraea showed a sharp and total loss of conductivity following the first fall frost (figure 10A). Similar observations have been made on Fraxinus excelsior [22], another ring porous species. Temperate ring porous species thus seem highly vulnerable to frost-induced embolism. The situation is different for diffuse porous and conifer species. For diffuse porous trees, such as Acer [108] or Fagus [50], the increase in embolism is more gradual and reaches high degrees only after repeated periods of frost. Conifers exhibit another extreme situation because they do not seem to suffer at all from winter embolism. It has been argued that freezing-induced embolism can limit the growth, survival, and geographic distribution of plant species [64, 94, $110,134]$. These studies suggest a link between xylem anatomy and the vulnerability to frost: the larger the conduit, the higher the vulnerability [42]. This link has clearly been established in a systematic study of the degree of late winter embolism in the xylem of many hard and softwood species $[133,146]$. A positive relationship was found between the specific hydraulic conductivity (which is primarily a function of conduit size) and the degree of embolism (figure 12). This is in opposition with what has been shown in figure $9 E$.

Davis et al. [35], carried out a technique which enabled them to consolidate more precisely this result. They showed that plants with mean conduit diameter above $30 / 40 \mu \mathrm{m}$ are extremely sensitive to cavitation by freezing, even for a modest xylem pressure (say $-0.5 \mathrm{MPa}$ ). Therefore, besides their specific vulnerability to summer embolism, species having large conduits will have an additional sensitivity to winter cavitation: under the same water stress conditions (as determined by xylem water potential) they will have more chance to be embolised during period of below zero temperature than during period of mild temperatures. This is well illustrated (figure 10B): Betula occidentalis having mean diameter conduits much larger than Abies lasiocarpa is therefore much more susceptible to freezing-induced cavitation. 


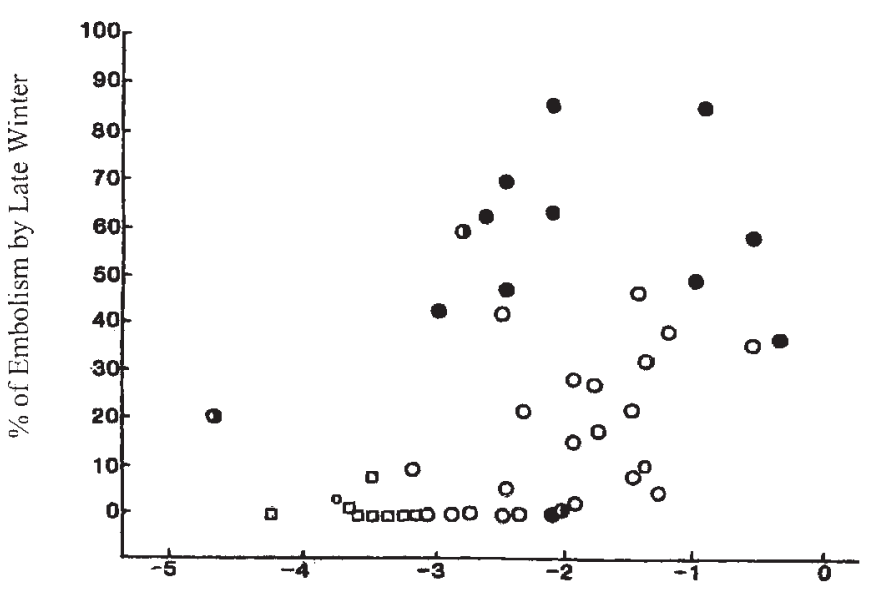

Log Maximum Specific Conductivity $\left(\mathrm{Kg}^{\mathrm{s}} \mathrm{s}^{-1} \cdot \mathrm{MPa}^{-1} \cdot \mathrm{m} \times 10^{-5}\right)$

Figure 12. Interspecific vulnerability to frost-induced embolism. The degree of xylem embolism was measured at the end of the winter for a large number of conifers (open squares) diffuse-porous (open circles) and ring-porous species (closed circles). This degree of embolism is expressed as a function of the xylem specific hydraulic conductivity which primarily correlates with conduit sizes: the larger the conduits, the higher the conductivity, the higher the embolism at late winter time. See also figure 10 (from [146]).

\subsection{The "frost-thaw" explanation}

Why should larger conduits be more prone to winter embolism? Our current explanation is based on a frost-thaw mechanism. When sap temperature drops a few degrees below $0{ }^{\circ} \mathrm{C}$, ice forms which creates air bubbles (air is almost not soluble in ice). It is assumed that during the thawing, when xylem tensions exceed a critical value, air bubbles are progressively released to the liquid phase and air-water menisci are created (figure 13).

As it can be deduced from the above discussion (figure 13), for a bubble of air to be stable, neither increasing or decreasing in size, the pressure difference, $\mathrm{P}_{\mathrm{g}}-\mathrm{P}_{\mathrm{l}}$, between the gas and the liquid phases must be equal to $4 \tau / \mathrm{d}$ (see capillary equation above). Or we can say if $\mathrm{P}_{1}<\left(\mathrm{P}_{\mathrm{g}}-4 \tau / \mathrm{d}\right)$ the bubble will expand to fill the whole conduit. The larger the initial size of the bubble, i.e., the larger the diameter of the conduit, then the closer can be $\mathrm{P}_{1}$ to $\mathrm{P}_{\mathrm{g}}$, i.e. the smaller the tension in the liquid to produce indefinite expansion and therefore gas filling of the conduit. Larger conduits are more vulnerable probably because bubbles are initially larger. The initial size of the bubbles can explain differences between species but cannot explain alone all the observations. In Fagus sylvatica for instance it has been recently observed [65] that young terminal shoots were more vulnerable than larger xylem segments which contradicts the conduit size-vulnerability relationship. Under controlled conditions, it was established that the terminal shoots were freezing and thawing before the

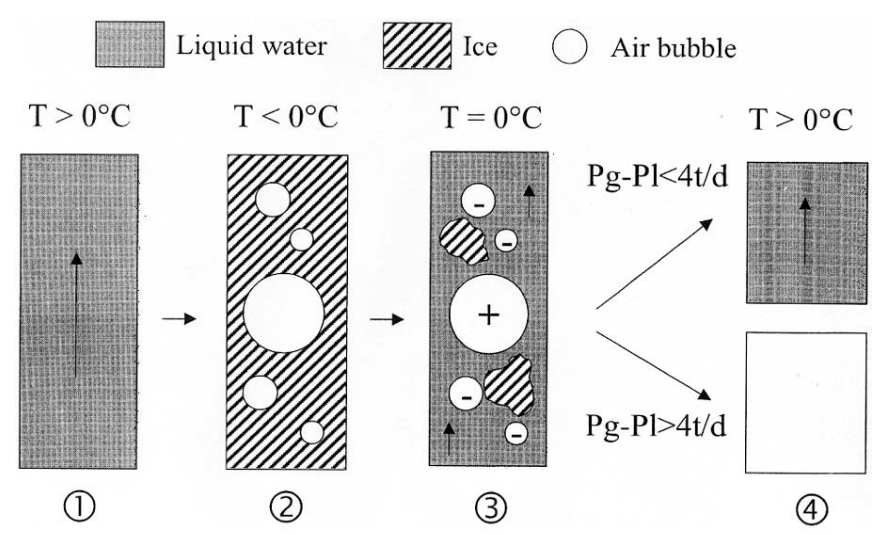

Figure 13. Mechanism of frost-induced embolism. The breakdown of water columns in xylem conduits following a frost-thaw event is probably due to the expansion of air bubbles formed during sap freezing. Tensions developed in the xylem at thawing are large enough to prevent the collapse of the largest bubbles caused by their surface tension. When temperatures decrease below $0{ }^{\circ} \mathrm{C}$, the liquide column of sap freezes and ice forms (2). Gas being much less soluble in ice than in the liquid sap, bubbles of different sizes appear (2). When temperatures increase above $0{ }^{\circ} \mathrm{C}$, ice sap thaws (3). Depending on their initial size and on the xylem tension at thawing, bubbles will either colapse (the smaller ones) or, in the contrary expand (the larger ones) (4). $\mathrm{Pg}=$ gas pressure of the bubbles; $\mathrm{Pl}=$ xylem sap pressure; $\mathrm{t}=$ surface tension of the sap; $d=$ conduit diameter; $\mathrm{T}=$ temperature.

remainder of the branch. This suggests that on freezing, water was expulsed from the apex (due to ice expansion). On thawing, this water deficit will induce high hydrostatic tensions. In beech, the development of hydrostatic tensions might determine the formation of embolism more than the sizes of air bubbles alone.

Recently Cochard et al. [26] have argued that vessel embolism occurs during the freezing phase in cryo-scanning electron microscopy observations. However the volume of air present in the vessels appears to be much greater than can be accounted for by the volume of air dissolved in the sap. This result suggests that we are far from having a clear understanding of the underlying physics governing the processes that occurs during frost-thaw cycles.

If trees experience high loss of hydraulic conductivity during winter, how can they cope with this situation when sap flow is reactivated in spring? Several authors $[3,50,105$, $108,112]$ have suggested that positive pressures in the xylem, during spring in particular, can have important implication for dissolution of freezing-induced embolism in temperate woody plants. Zhu et al. [151] found that in Betula alleghaniensis Britt., freezing damage to roots resulted in lower spring root pressures, less recovery from winter embolism, and higher shoot dieback.

Although most authors have considered positive pressures in the xylem to be important for dissolving embolism [3, 50, $55,105,129,139]$, mechanisms of winter pressure formation 
remain poorly understood. The most studied plants in this regard are species of Acer, for which there are several hundred papers dealing with the flow of maple sap $[60,74,80,88$, 122]. It is clear that in Acer, winter xylem pressures are derived from the stem and not the root. The sap exudation from the stumps of felled trees at that time of year is negligible whereas copious exudation occurs from excised shoots [73, 119]. Proposed mechanisms in Acer can be categorized into either "physical models" or "vitalistic models". According to physical models, the winter pressures are due strictly to freeze-thaw events [87, 122]. In contrast, according to vitalistic models, activities of living cells in the xylem are required for pressure buildup [59, 73, 74, 148]. It is known that at low, non-freezing temperatures, starch in stem parenchyma cells is broken down into sugars, especially sucrose [75]. Although sucrose appears to play a role in the pressure build-up in Acer stems, the buildup of sucrose is apoplastic and the osmotic role of sucrose in the formation of stem pressures has been questioned [30,60]. It has also been suggested that the living parenchyma cells are crucial for gas production, leading to temperature dependent changes in gas pressure in the air spaces within the wood fibres [101].

As in Acer, walnut trees (Juglans regia L.) have been observed to display positive pressures in the xylem sap during the winter, autumn and spring. Autumn and spring xylem pressures appeared to be of root origin and were positively correlated with soil temperature [44]. Winter stem pressure was associated with low temperatures and with high sugar concentrations in the xylem sap [2,7]. A simple osmotic model could account for the modest positive winter pressures at low, non-freezing temperatures, but not for the synergistic effects of freeze/thaw cycles.

Many other species lack such high pressurization periods (Quercus, Fraxinus, Castanea, Conifers, etc.). Therefore, conduits embolised during winter time remain permanently non-functional and may eventually become plugged by tyloses [15]. New functional vessels are then produced before leaf expansion and will insure most of the sap supply to the leaves during the growing season [49]. Species not suffering from winter damages or capable of reactivating their xylem conduits can, on contrary, rely on their sapwood to supply the new leaves with water. For theses species the new ring growth is delayed and occurs only after full leaf expansion. Tree phenology in spring may thus correlate with their xylem history. However, has mentioned above, recent results show that active (?) refilling can also take place in the presence of high xylem tension; however the mechanism underlying this process has not yet been identified $[55,139,156]$.

A detailed example of study concerning the mechanisms of xylem recovery from winter embolism can be found [27]. In mature beech trees, hydraulic conductivity in the terminal branches decreased progressively during winter. Two periods of recovery have been identified. The first occurred early in the spring before bud break and during the period of positive xylem pressure measured at the base of the tree trunk. Active refilling of the embolized vessels caused the recovery. The second recovery of hydraulic conductivity occurred after bud break when the cambial activity resumes, producing new functional conduits. Therefore two mechanisms whose effects can vary according to climatic conditions and species, can explain shoot hydraulic recovery of broadleaf trees in the spring. Figure 14 presents a schematic representation of the progression and recovery of embolism for a current beech year shoot (formed in year $\mathrm{n}$ ). In (1) a cross section of the current-year shoot is shown in late summer of year $n$, when cambial activity has ceased and when all xylem vessels are still filled with water: no embolism, hydraulic conductivity equal to its maximum value, e.g. when the shoot is fully hydrated, $\mathrm{K}_{\mathrm{w}}=\mathrm{K}_{\mathrm{wn}}$, and PCL (\% loss of conductivity) is equal to zero. For the year $\mathrm{n}$, this maximum value is then $\mathrm{K}_{\mathrm{wn}}$. Following freeze-thaw events, some vessels become filled with air and PCL increases up to a more or less important value, $\alpha$ in late winter (2). Then two possibilities can take place. The first is that vessels do not refill before the onset of ring development. The reduction of PCL value $\alpha$, will only be possible by the formation of new vessels and will be a function of the increase of the xylem surface $A_{n+1}$ and $K_{(w n+1)}\left(K_{w}\right.$ of the new ring). In this case $\mathrm{K}_{\mathrm{w}}$ increases in comparison with its previous value, because the growth produces more new functional xylem than the remaining embolized vessels (5). The second possibility is when positive pressures can take place during early spring and refill some embolized vessels. The residual PLC, $\beta$, will therefore becomes less than $\alpha$ (3). Later on, the cambial reactivation will further decreases of PCL to a value $<\beta$ (4). Therefore the paths (2) $\rightarrow$ (3) $\rightarrow$ (4) and (2) $\rightarrow$ (5) can be differentiated by comparing concurrent changes in PLC and $\mathrm{K}_{\mathrm{w}}$. The first with its refilling step (walnut, maple) should lead to a residual embolism lower than the second (oak, ash).

\section{THE COUPLING BETWEEN HYDRAULIC AND STOMATAL CONDUCTANCES}

Although the behavior of stomata in the presence of various stress (water, light, $\mathrm{CO}_{2}$ ) is well established, the underlying mechanisms remain largely unknown. In the presence of soil water deficits for instance, stomata gradually close which reduces leaf water loss. The production of specific hormones (ABA) by roots has been proposed as a coupling factor between the stomatal aperture and the soil water deficit [120]. In this part we will describe an alternative coupling between stomatal behavior and hydraulic properties.

\subsection{Theoretical and experimental relationships between transpiration and leaf water potential during a progressive soil drought}

According to the Ohm's law analogy, there is a simple relationship, for steady state conditions, between leaf transpiration and the average leaf water potential: 


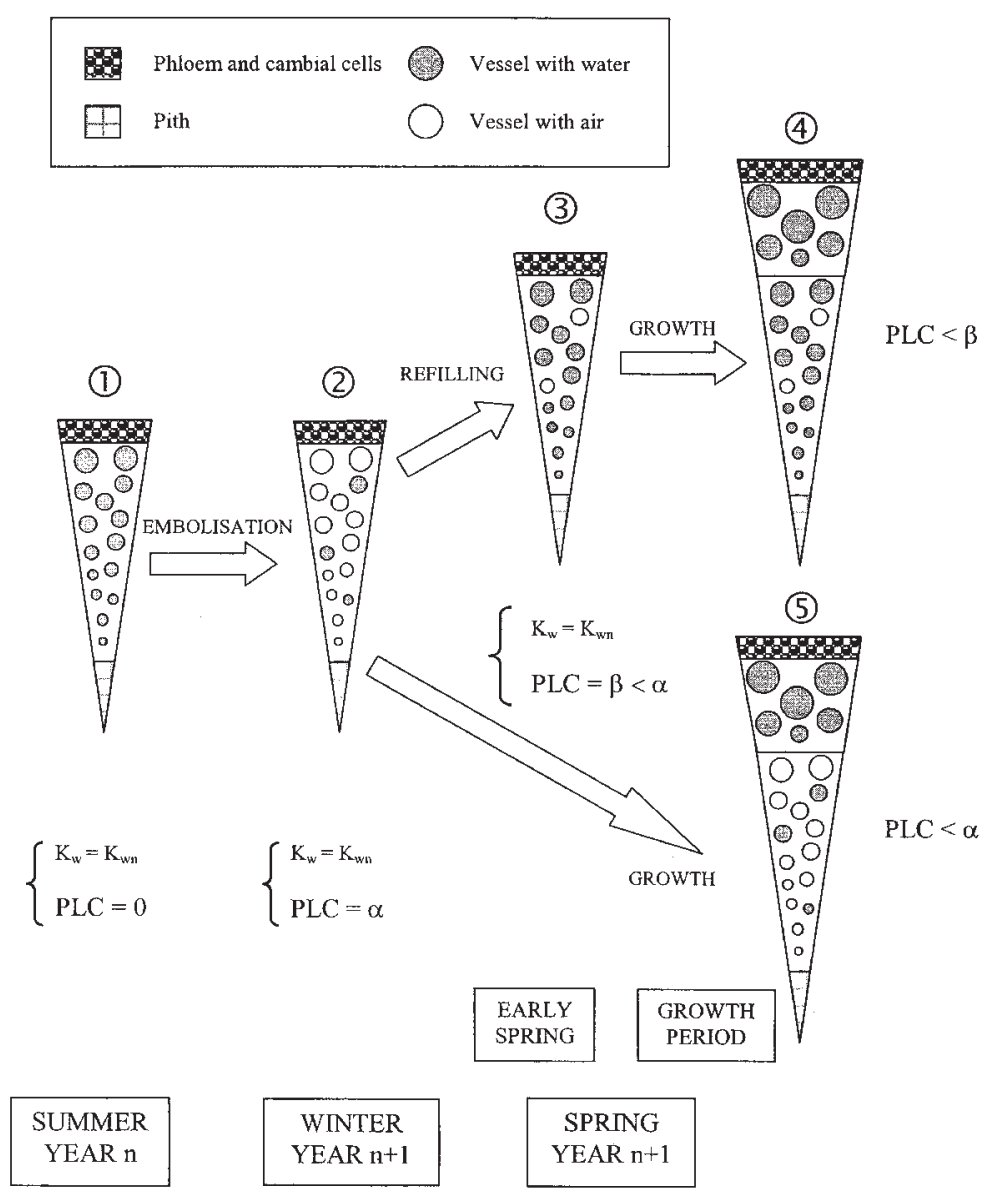

Figure 14. Schematic representation of progression and recovery of embolism for a current-year shoot (formed in year $n$ ) of beech. Two main phenomena contribute to this recovery: refilling of already build vessels and production of new vessels. More explanations in the text (from [27]).

$$
\Psi_{\text {leaf }}=\Psi_{\text {soil }}-\mathrm{F} \times \mathrm{R}_{\text {plant }}
$$

where $\Psi_{\text {leaf }}$ and $\Psi_{\text {soil }}$ are the leaf and soil water potentials $(\mathrm{MPa}), \mathrm{F}$ the whole plant transpiration rate $\left(\mathrm{mmol} \mathrm{s}^{-1}\right)$ and $\mathrm{R}_{\text {plant }}\left(\mathrm{mmol} \mathrm{s}^{-1} \mathrm{MPa}^{-1}\right.$ ) a coefficient that we call the "whole plant hydraulic resistance" by analogy to an electrical circuit. $\mathrm{R}_{\text {plant }}$ includes all the hydraulic resistances along the sap pathway from the soil to the leaves. Experimental relationships between $\mathrm{F}$ and $\Psi_{\text {leaf }}$ have been established for many species. The relationships are usually linear, but may also be curvilinear. The latter situation might be caused by nonsteady state conditions or variable $\mathrm{R}_{\text {plant }}$ resistances. [69] followed the $\Psi_{\text {leaf }}$ vs. F (sap flux density) relationships in a natural stand of Picea abies during a progressive soil drought (figure 15A). In control the relationships are close to linear, suggesting that $\mathrm{R}_{\text {plant }}$ was independent of the transpiration rate. However, $\mathrm{R}_{\text {plant }}$ varied considerably during the development of drought as indicated by the increase of slope. This result is important because it demonstrates that considerable changes in the plant hydraulic system can occur during a water shortage. The leaf water potential is therefore a poor estimate of the plant capacity to extract water from the soil.

When derived from the $\mathrm{F}$ vs. $\Psi_{\text {leaf }}$ relationships, $R_{\text {plant }}$ integrates soil, vascular and non vascular plant resistances. The question is then to know which resistance increases the most during a drought period?

\subsection{The increase in soil-root resistance}

Further observations during the previous study suggested that the increase in $\mathrm{R}_{\text {plant }}$ is most likely located at the soil-root interface or in the bulk soil itself. For instance, Lu [68] followed the changes in branch resistance $\mathrm{R}_{\text {branch }}$. Contrary to $\mathrm{R}_{\text {plant }}, \mathrm{R}_{\text {branch }}$ was nearly constant all through the drought period (figure $15 C$ ). The increase in $\mathrm{R}_{\text {plant }}$ could not be ascribed to cavitation events in the branch systems. Furthermore, the decrease in $\mathrm{R}_{\text {plant }}$ was reversed after soil rehydration. Because loss of conductivity due to cavitation is irreversible in conifers, it was therefore unlikely that the change in $\mathrm{R}_{\text {plant }}$ was located in the xylem system. In Picea, most of the droughtinduced variation in $\mathrm{R}_{\text {plant }}$ was therefore due to a reversible extra-vascular phenomenon. However, if the impact of xylem cavitation was only minimal in this study, this was probably the result of an active stomatal regulation. This is illustrated 

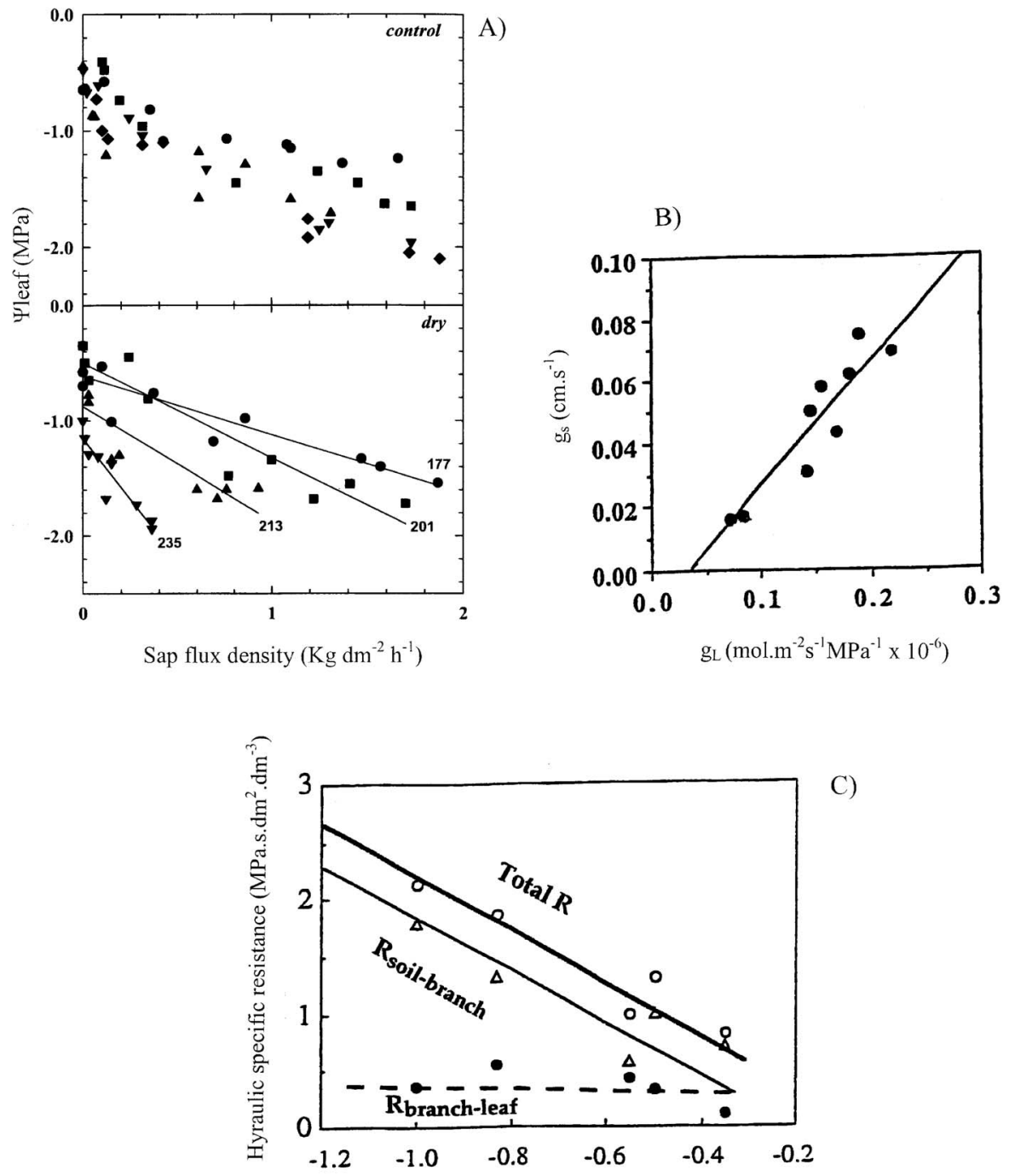

C)

Predawn soil water potential (Mpa)

Figure 15. A: Tree transpiration (x axis) versus leaf water potential (y axis) in Picea abies for well-watered plant (control) and increasing soil drought (dry, numbers refer to days of the year). The relationships were rather linear, but were clearly modified by water stress: the whole plant hydraulic resistance, which is represented by the slope of the relationships, was increased during drought (from [69]). B: Changes in whole plant hydraulic resistance during drought. Total hydraulic resistances derived from the slopes in A, are expressed as a function of predawn (soil) leaf water potentials. Total resistance is calculated from the following expression $\Delta \Psi$ (soil-leaf) $=\mathrm{F} / \mathrm{R}_{\text {total }}$ where $\mathrm{F}$ is the transpiration per sap wood surface; $\mathrm{R}_{\text {total }}$ was divided into two components: soil to branch and branch to leaf. The increase in total $\mathrm{R}$ with drought was located in the soilbranch pathway and very likely in the soil-root compartment (from [69]). C: Coupling between total hydraulic conductance $\mathrm{g}_{\mathrm{L}}$ and stomatal conductance $\mathrm{g}_{\mathrm{s}}$. Midday stomatal conductances were linearly related to whole plant hydraulic conductances in the Picea experiment (from [68]). The decrease in hydraulic conductance during drought caused a stomatal closure and hence a reduction of transpiration.

in figure $15 B$, where the midday leaf stomatal conductance $\left(\mathrm{g}_{\mathrm{s}}\right)$ is expressed as a function of the whole plant hydraulic conductance $\left(\mathrm{g}_{\mathrm{L}}=1 / \mathrm{R}_{\text {plant }}\right)$. A decrease in $\mathrm{g}_{\mathrm{s}}$ during the drought development was coupled with a decrease in $\mathrm{g}_{\mathrm{L}}$. The result of this stomatal regulation is visible in figure 15: the maximum transpiration rate was reduced with increasing soil drought, and, consequently, the drop in $\Psi_{\text {leaf }}$ was minimized. Various physiological reasons could explain why the plant tended to minimize the drop of $\Psi_{\text {leaf }}$ during a water shortage (to prevent loss of cell turgor for instance). Another possible reason might involve a protection against xylem cavitation.

\subsection{The consequence of xylem vulnerability}

When the xylem water potential $\left(\Psi_{\text {xylem }}\right)$ drops below a threshold value $\left(\Psi_{\text {cav }}\right)$ then cavitation occurs. It has been 


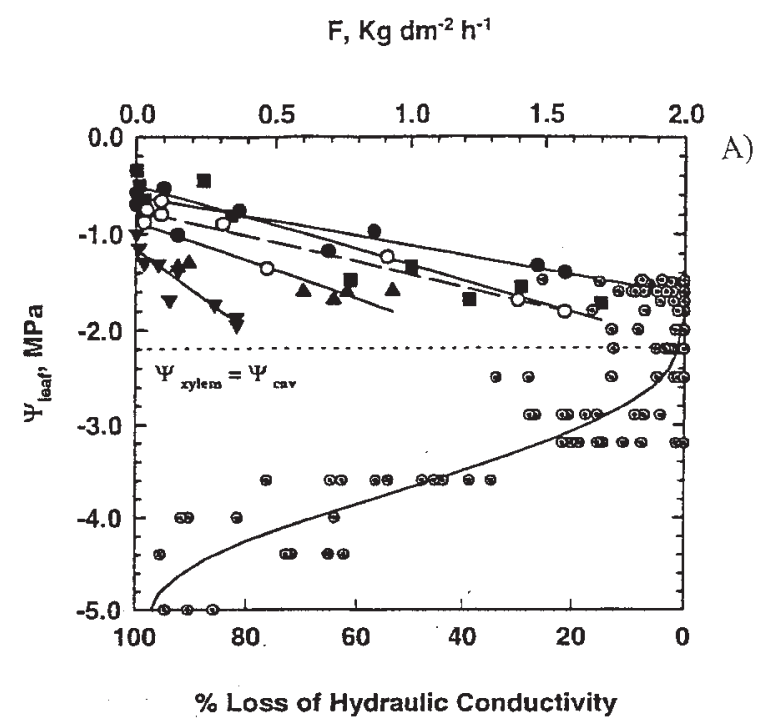

B)

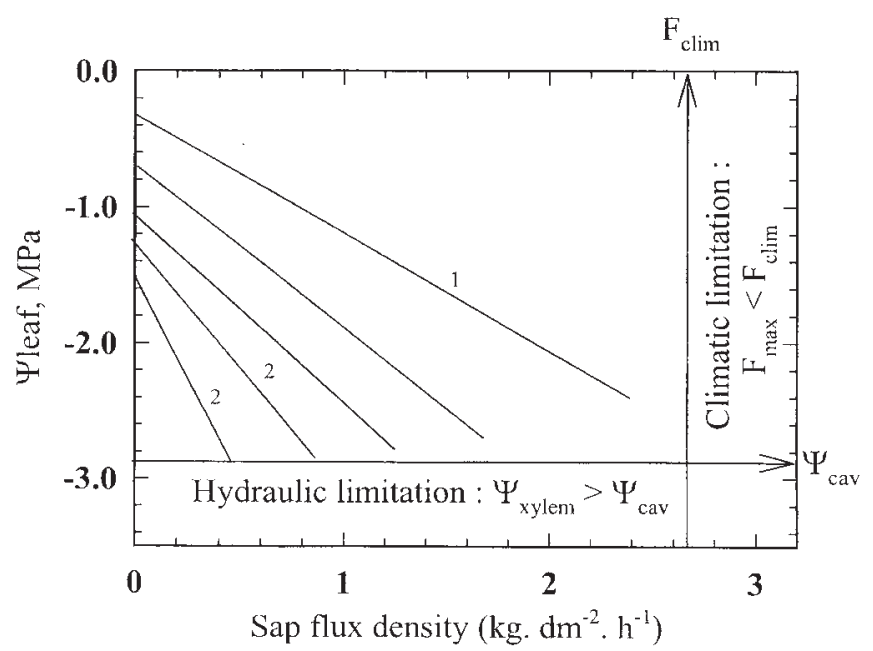

Figure 16. A: Consequences of xylem vulnerability on tree water relations. The vulnerability curve of Picea abies $\left(\Psi_{\text {leaf }}\right.$ vs. percent loss of conductivity) shows a steep increase of embolism for water potentials lower than $\Psi_{\text {cav }}=-2.2 \mathrm{MPa}$ (horizontal line). For well watered trees $\Psi_{\text {leaf }}$ was close to $-2 \mathrm{MPa}$ but always remained above $\Psi_{\text {cav }}$ during water stress because of a coupling between maximum transpiration rates $(\mathrm{F}$, lower $\mathrm{x}$ axis) and whole plant hydraulic conductance (from [69], modified). B: Factor controlling maximum water loss. Flux/Potential relationships help in understanding daily maximum transpiration rates in Quercus. For well watered trees (line 1), $\mathrm{F}_{\max }$ is probably limited by climatic conditions such as light level, air vapor pressure deficit or $\mathrm{CO}_{2}$ concentration. However, for water-stressed trees (lines 2), whole hydraulic resistances increased (steeper slopes) causing $\Psi_{\text {xylem }}$ to reach values close to $\Psi_{\text {cav }}$. The xylem vulnerability set an hydraulic limitation to oak water relations (from [20], modified). previously demonstrated that $\Psi_{\text {cav }}$ is determined only by ultra-anatomical properties of wall pits (figure 11). The onset of cavitation is then given by the simple physical law shown in Section 3.4. For any conduit, if $\Psi_{\text {xylem }}$ becomes lower (more negative) than its specific $\Psi_{\text {cav }}$ value then cavitation must occur. Therefore, $\Psi_{\text {cav }}$ puts a functional limitation to the xylem physiology. The question now is: how close is $\Psi_{\text {cav }}$ to the $\Psi_{\text {xylem }}$ values experienced during a drought period?

Figure 16A compares the time-course of midday $\Psi_{\text {leaf }}$ values with the vulnerability curve established on the xylem of the same species, Picea abies. It is first important to note that because of large extra-vascular leaf resistances [133, 137], $\Psi_{\text {leaf }}$ is significantly lower than $\Psi_{\text {xylem }}$. However when stomatal, soil and soil-root resistances are increasing during drought periods, $\Psi_{\text {leaf }}$ and $\Psi_{\text {xylem }}$ agree more closely [22]. Therefore, when the soil drought was maximal, $\Psi_{\text {xylem }}$ was very close to $\Psi_{\text {cav }}$ (within a few bars). In Picea, the control of leaf water loss by an active stomatal closure prevented $\Psi_{\text {xylem }}$ from reaching damaging values, and thus contributed to the maintenance of xylem integrity. The consequence of xylem vulnerability is thus to put an effective functional limitation to the maximum transpiration rate of a plant.

\subsection{Factors controlling the daily maximum water loss}

From the previous results it is now possible to see what are the main controlling factors of the daily maximum water loss $\left(\mathrm{F}_{\text {max }}\right)$. The maximum transpiration rate depends in the first instance on ambient climatic conditions (mainly light, vpd and $\left.\left[\mathrm{CO}_{2}\right]\right)$. For each day there is a climatic maximum water loss $\mathrm{F}_{\text {clim }}$ and $\mathrm{F}_{\max }$ can never exceed $\mathrm{F}_{\text {clim }}$. According to what has been discussed in the previous paragraph, we can also define a maximum water loss $\left(\mathrm{F}_{\text {cav }}\right)$ based on the hypothesis that $\Psi_{\text {xylem }}>\Psi_{\text {cav }}$ to maintain the xylem integrity. Combining with equation of Section 4.1, we have:

$$
\Psi_{\text {xylem }}>\Psi_{\text {cav }}=\Psi_{\text {soil }}-F_{\text {cav }} \times R_{\text {soil-xylem }}
$$

or

$$
\mathrm{F}_{\text {max }}<\mathrm{F}_{\text {cav }}=\left(\Psi_{\text {soil }}-\Psi_{\text {cav }}\right) / \mathrm{R}_{\text {soil-xylem }}
$$

where $R_{\text {soil-xylem }}$ is the hydraulic resistance to the sap pathway from the soil to any xylem segment.

To illustrate the relationships between $\mathrm{F}_{\text {clim }}$ and $\mathrm{F}_{\text {cav }}$, a diagram (figure $16 B$ ), summarizes a data set very similar to the previous Picea experiment (figure 16A) but for a Quercus species [20]. When $R_{\text {plant }}$ (and $R_{\text {soil-xylem }}$ ) is low (high soil humidity) then $\mathrm{F}_{\text {clim }}$ is lower than the theoretical $\mathrm{F}_{\text {cav }} . \mathrm{F}_{\max }$ is then limited only by external climatic conditions, $\mathrm{F}_{\text {clim }}$. However, when $R_{\text {plant }}$ increases because of soil drought, $F_{\text {cav }}$ becomes lower than $\mathrm{F}_{\text {clim }}$ and an internal hydraulic limitation appears. The factors controlling $\mathrm{F}_{\max }$ are thus both internal and external to the plant. The fact that Quercus and Picea (and probably most species) are operating close to the point of xylem dysfunction and that $R_{\text {plant }}$ is soon and drastically increased by drought implies that these trees are rapidly facing an internal 

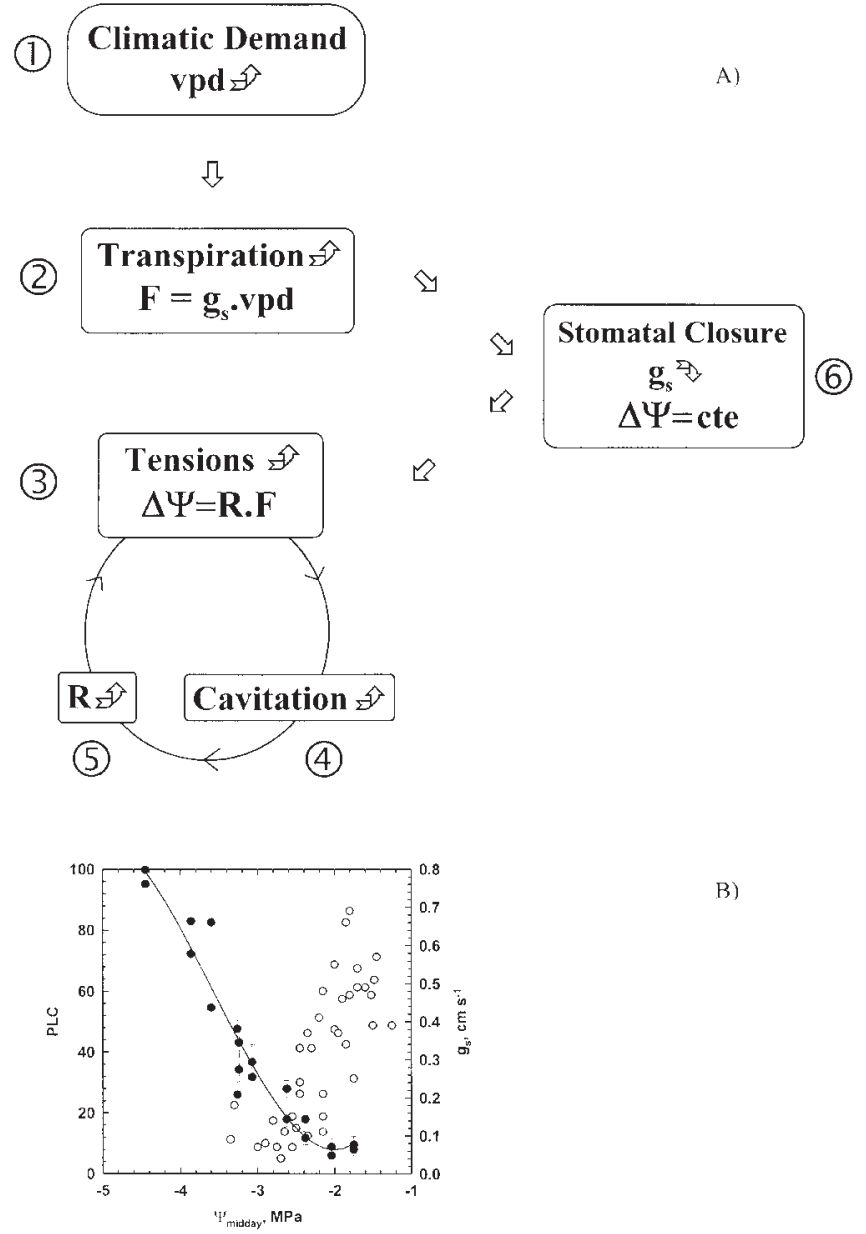

B)

Figure 17. A: The embolism cycle: the higher the transpiration, the lower the $\Psi_{\text {xylem }}$, the higher the risk of cavitation; for most plant species, this "vicious" or run-away embolism circle is stopped by an active stomatal closure stomatal. B: This is the case for Quercus petraea: stomata (open symbols) are completely closed before xylem embolism develops (closed symbols). More explanations in the text (from [20]).

hydraulic limitation which induces a stomatal closure preventing a "runaway embolism" [125].

\subsection{Stomatal closure can prevent "runaway embolism"}

When the blockage of xylem conduits through embolism leads to reduced hydraulic conductance an increase of tension is required in the remaining vessels to maintain the same water flow to leaves; then more embolism and tension will be generated in a vicious circle called "runaway" or "catastrophic embolism". The cycle stops only when the xylem is fully embolised unless stomatal closure reduces the transpiration and hence the drop in $\Psi_{\text {xylem }}$. Figure $17 A$ illustrates the process. High climatic demand (large air vapor deficit, vpd, (1) ) causes high transpiration rates $\mathrm{F}\left(\mathrm{F}=\mathrm{g}_{\mathrm{s}} \times \mathrm{vpd}\right.$, where $\mathrm{g}_{\mathrm{s}}$ is the stomatal conductance, (2)) which may induce xylem water potential $(\Delta \Psi=\mathrm{R} \times \mathrm{F}$, where $\mathrm{R}$ is the plant hydraulic resistance, (3) lower than the cavitation threshold. Cavitation of the conducting elements (4) is followed by embolism causing loss of hydraulic conductivity (5), lowering furthermore the water potential (3) then causing more cavitation (4). This is the "runaway embolism circle". It is supposed that for most plant species, this circle is stopped by an active stomatal closure (6) that reduces transpiration and keeps xylem potential above the cavitation threshold. Figure $17 B$ shows the case for Quercus petraea [20]: stomata are completely closed (open symbols) before xylem embolism develops (closed symbols).

Stomatal closure appears then as a key mechanism in the protection against lethal xylem dysfunction's. Experimental evidence for this concept is difficult to obtain because stomata close efficiently, which stops the cycle. Runaway embolism is therefore a kind of "limiting concept" deduced from models of the dynamics of water flow and xylem blockage [61, 124]. Sperry et al. [114] extended this concept by including the entire soil-leaf continuum and the combined effects of hydraulic failure (for a critical value of $\Psi$ ) which can happen at the soil-root contact (rhizosphere) or within the vascular system. In particular, they showed two important features. When the root-to-leaf area ratio is low, the soil has a coarse texture, and the involved plant species is resistant to cavitation, then the weak point is at the soil-root contact. In contrast, when the root to leaf ratio is higher, the soil has a fine texture and the species is vulnerable to cavitation, then the weak point is the vascular pathway. It is worth noting, however, that in this model, the radial resistance of roots is not taken into account. Hacke et al. [52] argued that because this model gives "a reasonable fit to the seasonal pattern of transpiration and water potential data, ..., by implication [it] suggests that changes in hydraulic conductance caused by processes not modeled, such as changes in radial conductance of roots, ..., were less important to the overall continuum conductance than changes modeled in soil and xylem". However, compensation effects of processes not taken into account in this model could lead to the same conclusion. In other words, this model as useful as it may be, does not necessarily prove that the radial resistance could not play an important role in particular situations. For example, it has been shown in desert plants that the radial resistance increases considerably during soil drying, as soon as the soil water potential starts to be lower than the root water potential [86]. This increase of the radial resistance (probably involving aquaporins, [77]) prevents root dehydration. Furthermore, it is important to remember that the few results reporting comparison between radial and total root resistance (see review article [117]), all concluded that the radial is larger than the longitudinal resistance. As a consequence, embolism in the root xylem should be quite important before affecting the global root resistance. In the present state of our knowledge, general conclusions regarding the respective importance of 
radial and longitudinal root resistance are premature. Large differences probably exist according to types and age of roots, species and environmental conditions.

Cochard et al. [21], studied the water relations of a Populus hybrid (trichocarpa $\times$ koreana) known to lack efficient stomatal closure in the presence of soil water stress. It was actually found that only stomata in mature leaves were unresponsive to water stress. Stomata from young expanding leaves were still responsive but lost their aperture control when aging. Soon after water withdrawal, high degrees of embolism appeared in mature leaf petioles and shoot internodes, but embolism steadily declined toward shoot apices. In other words, the better the control of stomatal aperture, the lower the degree of embolism. Where stomata were not capable of reducing leaf water loss, embolism occurred and leaves eventually fell. The "safety margin" for stomata seems very narrow because maximum loss of conductivity were noticed for leaves deviating of about $30 \%$ from the optimal complete closure. A similar result has been found on Betula occidentalis [111].

This point has been studied within different species by Sperry [115], who gives an estimate of the safety margin by comparing the xylem water potential $\Psi_{\mathrm{CT}}$, at $100 \%$ loss of conductivity with the actual minimum xylem water potential $\Psi_{\min }$ experienced by 73 species. There is a significant correlation between $\Psi_{\mathrm{CT}}$ and $\Psi_{\min }$. Plants that are more drought resistant are also more resistant to cavitation. The safety margin, based on the difference $\Psi_{\min }-\Psi_{\mathrm{CT}}$ ranges from 1 to $0.5 \mathrm{MPa}$. As pointed out by Sperry: "These and other observations suggest that much of the stomatal closure observed during drought is a result of the amplifying effects of declining of the liquid hydraulic conductance from soil to leaf rather than a strictly proportional response to drying soil”. Results [28] with walnut trees submitted to water stress suggest that stomata were not responding to changes in $\Psi_{\text {soil }}$, root or shoot resistance per se, but rather to their impact on the rachis or leaf water potential. It can be concluded from all the published results that if a kind of coupling does exist between hydraulic and stomatal conductances to preserve the possibility of water flow from the soil to the leaves, the exact mechanism by which this coupling is regulated is still a matter of discussion. As pointed out by Comstock [29bis], "major questions remain unanswered on how water stress signals perceived at root and leaf locations are integrated at the guard cell to control stomatal behavior".

\section{CONCLUSIONS}

The hydraulic architecture approach is certainly the major new trend in tree water relations, which has emerged in the last decade. It brings together three different and so far very often completely separated ways of studying plant water relations. The first is the very classical and well-established Van den Honert approach (the use of the electrical analogy to deal with water transfer through the soil-plant-atmosphere continuum). The second is the application of the recently revisited and very much improved cohesion-tension theory. The last is quantitative anatomy of vessels and tree branching considerations [130, 133]. Although this approach is still very young it has already renewed many aspects of the way we look at tree water relations. It has already given new and valuable answers to old questions concerning the significance of ring and diffuse porousness [57]. It can be predicted without risk that in the near future this approach will continue to develop.

However, much more work should be done on speciesspecific xylem anatomy and especially on the changes with time in the more or less integrated network of connections between the roots and branches of the same tree. Recent works of André [8, 9] and Fujii and Hanato [46] have revealed many important new anatomical features of the xylem anatomy and showed how much our knowledge in this domain can be improved by appropriate techniques.

Likewise, Hacke et al. [53], have given evidence for an interesting quantitative anatomical feature. They showed a correlation between wood density and cavitation resistance: the more drought-tolerant the plant, the more negative the xylem pressure can become without cavitation, and the greater the wood density. It seems therefore that wood density is not only related to support of the plant against gravity, wind, snow, etc., but also to support the xylem pipeline against the collapsing by large negative pressure.

Concerning cavitation and drought-induced embolism, we have now well founded explanations. Nevertheless many questions need additional work. For example, does the presence of other substances within the sap (ions, inorganic acids, hormones, etc.), the variations of $\mathrm{pH}$ or other physical-chemical characteristics have an effect on cavitation? If, without doubt, cavitation in most of the cases, is closely linked to pit pore's size ("air seeding" explanation) is it the only way cavitation can occur? Which quantitative anatomical features will be necessary to model a vulnerability curve? The determining factors of the propagation of cavitation within a branch are also still very poorly known, just like those that determine and control of pit pore size and pit pore distribution. If genetics play, more or less directly, a part in the determination of this size it is also probable that either internal (physiological status at the time when vessels form, mechanical properties of the pit membrane) and external (climatic, etc.) conditions may be also important.

From the point of view of ecophysiological considerations, h.a. concepts are used in two different domains: drought resistance and freezing-induced xylem dysfunction. For drought resistance, there are increasing evidence that plant ability to lose water from leaves is also associated with its ability to supply leaves with water. Under these conditions, the specific relationships between the plant hydraulic conductivity and the tension resulting from cavitation leads, ipso facto, to the limits on the range of tension over which gas 
exchange can occur and makes clear the fact that large differences in drought tolerance between species correlate with these hydraulic limits. Besides, taking into account the variation of conductance in the two "bottlenecks" of the soil-plant continuum (soil-root zone and vascular pathway) has led to new suggestions for explanations concerning the possible linked evolution between root-shoot ratios and cavitation resistance in response to soil type and water availability: "Plants should be hydraulically compatible with their soil" [114]. This statement also expands the discussion on stomatal regulation. The process (chemical or/and hydraulic signal, ..., or something else) which allows the coupling between stomatal conductance and hydraulic conductance can be compared to a safety bell: although always present, it is the determining factor of stomatal regulation only when events in soil and climate threaten the functioning of the conducting system. Beside, as we know, many other factors influence the stomatal conductance. The problem is nevertheless to understand how these different kind of regulations work together. From this drought adaptation point of view, the already collected results (Cochard, unpublished) concerning the stomatal and hydraulic conductances relationships, suggest a first schematic classification of the tree species into three major groups (figure 18). Species from the first, and apparently most important group, at least among the experienced species, control loss of their hydraulic conductivity by stomatal closure: the value of $\Psi_{\text {xylem }}$ which provokes $10 \%$ loss of hydraulic conductivity also lead to a $90 \%$ of stomatal closure. Beside two other "strategies" seem to occur. One is formed by species (PP: Prunus persica) which maximizes stomatal conductance: for the $\Psi_{\text {xylem }}$ which lead to $10 \%$ loss of conductivity their stomatal closure is much less than $90 \%$. The other (CA: Cupressus arizonica) has the opposite behavior: it minimizes the loss hydraulic conductivity by closing its stomata at a $\Psi_{\text {xylem }}$ much higher than the one required to provoke $10 \%$ loss of hydraulic conductivity.

The second closed direction in which h.a. concepts are used and very useful is freezing-induced xylem dysfunction. In this regard, it is a reasonable temptation to say that there is a functional connection between the dominance of conifers within the very cold areas and the fact that, bearing very narrow tracheids, they are enable to resist to freeze-induced embolism, in opposition with broadleaf trees. Therefore as for drought resistance it seems that another anatomical feature is a key point to understand the resistance of trees to frost.

Progress in h.a. are also possible in a quite different direction: the partition of water fluxes between the different parts of a tree under given conditions of transpiration. Until now h.a. has given a mapping of the different hydraulic capabilities of the conducting system. It is like having the quantitative description of the hydraulic resistances of the tubing from an irrigation system: this does not give you the distribution of actual flows within the different parts of the system, which depends on the water headings (equivalent to the water poten-

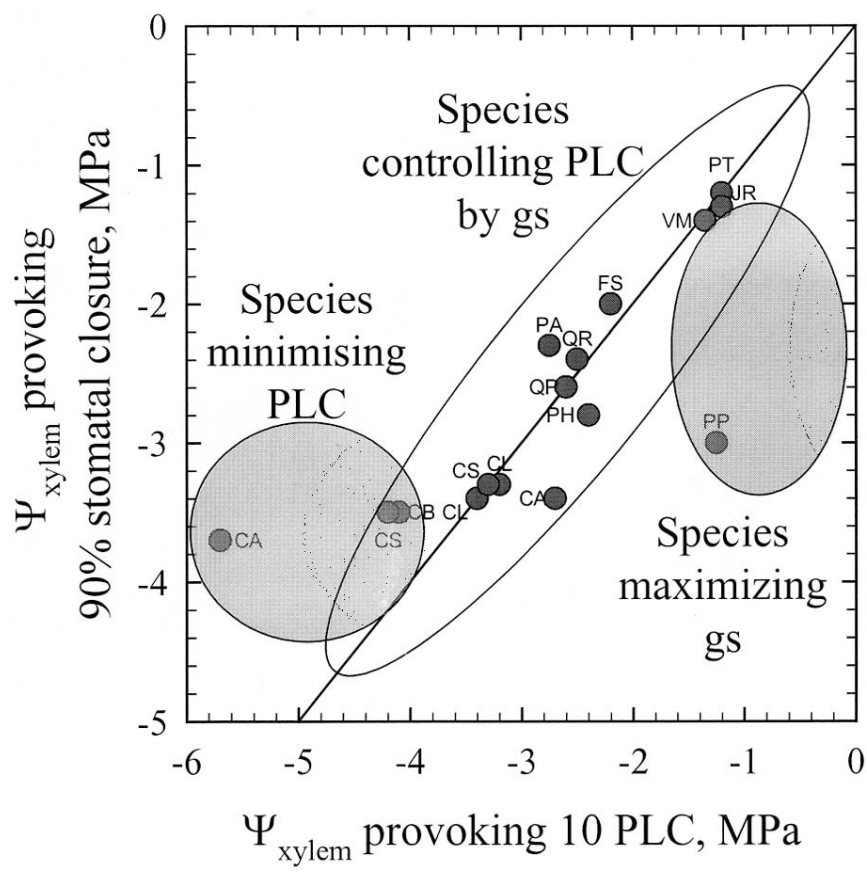

Figure 18. Hydraulic architecture of tree and drought. Three main groups can be distinguished. In the first, most important, trees control extension of embolism by stomatal closure. In the second, trees favour a large stomatal conductance $\mathrm{g}_{\mathrm{s}}$; in the last they seem to close their stomata before a significant degree of embolism can occur. (from Cochard, unpublished collected results): $\mathrm{PT}=$ Populus trichocarpa, [21]; JR = Juglans regia, (Cochard and Améglio, unpublished); $\mathrm{VM}=$ Vaccinum corymbosum, [6]; FS = Fagus sylvatica, [24]; PP = Prunus persica, [4]; PH = Pinus halepensis, (Froux and Huc, unpublished); $\mathrm{QR}=$ Quercus robur; $\mathrm{QP}=$ Quercus petraea, [20]; PA = Picea abies, [69]; CL = Cedrus libani, (Ladjal and Huc, unpublished); $\mathrm{CA}=$ Cedrus atlantica, (Froux and Huc, unpublished); $\mathrm{CS}=$ Cupressus sempervirens, (Froux and Huc, unpublished); $\mathrm{CB}=$ Cedrus brevifolia, (Ladjal and Huc, unpublished); $\mathrm{CA}=$ Cupressus arizonica, (Froux and Huc, unpublished).

tial differences) across the system. In order to have a better understanding of the water functioning of a tree we now need to get a spatial mapping of the real fluxes which flow within the various parts of a tree under given boundary conditions. As said in Section 2.2, this field has been opened, among others, by Roach [97]. To our knowledge, since that date, few attempts have been made to determine the patterns of water movement in trees, by using dyes as Roach did $[145,152]$ or methods allowing the quantification of flow along a branch or a root, or a sector of a trunk $[48,83,140]$. In other words we have still a very elementary knowledge of the distribution of absorption among the roots, how the water flux from any one root spreads out within the growth rings, thus reaching not only a single branch but a large part of the crown [154], how the distribution of fluxes along a tree is affected by pruning practices or by the decay of a major root, how the patterns of water movement within a tree change with soil drying and 
climatic conditions. A significant progress on that field will be realized by improving our knowledge about the anatomical connections between the root system and the shoot. Another most promising direction of research is the one where hydraulic architecture and "botanical architecture" meets as said, thirteen years ago by Zimmermann: "It will be of considerable interest to link hydraulic architecture types to the morphological tree-classification of Hallé Oldeman and Tomlinson [54], although one must realize that the morphology is an expression of all functional adaptations, not only the hydraulic one. It will also be of considerable interest to study developmental events such as the change of hydraulic properties of a lateral as it assumes the function of the main stem in sympodial branching, etc." [154]. We can formulate other questions: how does the hydraulic conductance of axes change with aging? Do the reiterated complexes have specific hydraulic characteristics? If the crown of an old tree is a true colony of individuals of various size, does this mean that these individuals present also some hydraulic specificity? There is a vast, open and promising field of research. Among different questions, this direction of research will probably help to solve the present debate on how hydraulics limits tree height and growth $[13,99]$.

Acknowlegements: We thank very much Jack Dainty for reading a first version of the manuscript and Frank Ewers for fruitful discussions and P. Martre for discussion on root resistance problems. We also wish to thanks the comments of the reviewers especially J.S., for his numerous comments which have been very helpful for improving the final version.

\section{APPENDIX: WATER POTENTIAL, PRESSURE, TENSION}

Either in the text or in the figures of this introduction, several different expressions have been used concerning the state of water in trees: water potential, xylem water potential, tension or pressure profiles. For the reader in a hurry it can be said that these different terms are, in the present context, more or less equivalent. For the reader not familiar with the water-plant terminology, and who wants to understand a little more, the following explanation should be of some help.

There are different possible definitions of the water status in a plant. Two types are in major use. The first is based on the mass of water present (ex.: the water content), the second on the energetic status of water. Water potential is a measure of the latter. Water potential $\Psi$ is an intensive (i.e., a quantity which is not dependent of the amount of water present on the plant sample, unlike the water content which is an extensive variable) thermodynamic variable. It is derived from the classical chemical potential $\mu$, which represents "the work involved in moving one mole $(18 \mathrm{~g})$ of water from a pool of pure water at atmospheric pressure, at the same temperature as the system under consideration, and at the zero level, to some arbitrary point in a system" [85]. It determines, under certain conditions, the water movements between the soil and the roots, or two different parts of the same plant, or the leaves and the atmosphere for example. The water potential, $\Psi$, of the water present within a system containing water (soil, plant tissue, wood, fruit, seed, paper, etc.), is given by the following expression:

$$
\Psi=\left(\mu_{w}-\mu^{o}{ }_{w}\right) / V_{w}=P+\Pi+\rho_{w} \times g \times h
$$

where $\Psi$ is the water potential in bars, or megaPascals, MPa. (1 bar $\approx 1$ atmosphere; $1 \mathrm{MPa}=10$ bars $) ; \mu_{\mathrm{w}}^{\circ}$ is the chemical potential of water in the standard status (i.e., pure water at atmospheric pressure and same temperature as the system being considered); $\mu_{w}$ is the chemical potential of the water in the plant; $\mathrm{V}_{\mathrm{w}}$ is the molar volume of water $\left(18 \mathrm{~cm}^{3}\right.$ per mole). $\mathrm{P}$ is the hydrostatic pressure (or hydrostatic potential, or pressure potential), $\Pi$ the osmotic potential (osmotic potential $=-$ osmotic pressure). The third term is a gravitational term, which accounts for the vertical position above a standard level. As work must be performed to raise an object in the gravitational field of the earth, the vertical position affects the chemical and thus the water potentials. If water moves $10 \mathrm{~m}$ vertically upward in a tree, the gravitational term changes: its contribution to the water potential is $0.1 \mathrm{MPa}$. In other words, in a standing hydrostatic 10 meter high column of water the difference of water potential, only due to the difference of elevation, is $0.1 \mathrm{MPa}$. Therefore this is a lower limit (named gravitational potential gradient in figure 7A) for tension gradients within a tree and Schefflera morototoni (figure 8) provides an example of an extremely efficient conducting system.

According to the above equation, $\Psi$ is expressed as energy per unit of volume, i.e. as pressure. Therefore $\Psi$ units are pressure units. A difference of $\Psi$ between two locations in hydraulic continuity indicates that water is not in equilibrium, so there will be a tendency for water to move from the place where $\Psi$ is high to a place where $\Psi$ is lower.

When the water content of a tissue sample is maximal, this state is called that of full turgidity; the corresponding water potential is zero. All other water status situations, with lower water content in the tissue, correspond to negative values of $\Psi$. In plants, most of the time, $\Psi$ is negative. Under these conditions water will flow from negative to more negative $\Psi$.

In the equation above and for a cell, $\mathrm{P}$ is the pressure (greater than atmospheric pressure) exerted by the cell wall within the cell. It is a positive term. However for a conducting element, $\mathrm{P}$ is a tension (a subatmopheric or more generally, a negative pressure). Therefore for a vessel or a tracheid, $P$ is negative! $\Pi$ is the osmotic potential of the cell sap; with the convention of sign used in the above equation $(+\Pi)$ it is negative.

Let us give an example of the application of the above equation for a cell and for a conducting element. For a root or leaf cell not at full turgidity, $\mathrm{P}$ is positive (+7 bars) and $\Pi$ more negative ( -12 bars). The resulting $\Psi$ is negative: $\Psi=7+(-12)=-5$ bars. If the cell is at full turgidity, $\mathrm{P}=-\Pi$ and $\Psi=0$. For a conducting element the tension can be, -10 bars for example. But the osmotic potential of the xylem sap is generally very close to zero, -0.5 bars for example. The resulting $\Psi$ is also negative: $\Psi=-10+(-0.5)=-10.5$ bars. As can be seen for the vascular elements, $\Psi$ and $\mathrm{P}$ are very close. Therefore one can often confuse both terms and approximate the total water potential of the xylem sap by its tension.

Concerning "tension" we point out the problem of sign. Most people in the literature refer to tension as a positive number, e.g. a xylem tension of $+1.5 \mathrm{MPa}$ equals a pressure (or water potential) of $-1.5 \mathrm{MPa}$. So tension increases as water potential or pressure potential decreases. We therefore accept this conventional use of the word "tension" which is satisfying from the semantic point of view. Nevertheless we want to express our feeling that such a choice is at the same time confusing for non-specialists and not consistent from the physical point of view for the following reasons:

- The tension of the water in the xylem is really at a negative pressure; by contrast, the turgor pressure is really a positive pressure 
exerted by the cell wall. The physical state of water at +5 bars $(0.5 \mathrm{MPa})$ is different from the state at -5 bars. No cavitation and embolism will occur at positive pressure; they can appear in water under tension. Why is this important difference cancelled by considering the tension as a positive number, especially if, at the same time, it is recognized that tension is a negative pressure?

- This difference between positive pressure and tension (negative pressure) is basic for distinguishing the effects of root pressure and of transpiration on the xylem sap and for understanding the difference between phloem and xylem transport.

- As outlined above, since the osmotic pressure of the xylem sap is often very low, the water potential of the xylem can be approximated by its tension; it is confusing then to express this approximation as a positive value. Furthermore with this convention, we must also change the sign in front of $\mathrm{P}$ in the above equation: "-_" if $\mathrm{P}$ is a tension, "+" if $\mathrm{P}$ is a turgor pressure!

From the understanding point of view, the simplest convention is the following. A negative water potential is called a tension (we will speak of a tension of $-1 \mathrm{MPa}$ ); a positive water potential is called a pressure (we will speak of a root or stem pressure of $0.1 \mathrm{MPa}$ ).

Due to this, in this paper we have avoided use of the term "tension" except when no confusion was possible.

For additional information see more general reviews [14, 34, $116,121]$ or treatises $[63,85]$.

\section{REFERENCES}

[1] Améglio T., Morizet J., Cruiziat P., Martignac M., The effects of root temperature on water flux, potential and root resistance in sunflower, Agronomie 10 (1990) 331-340.

[2] Améglio T., Cruiziat P., Alternance tension/pression de la sève dans le xylème chez le noyer pendant l'hiver : rôle des températures, C. R. Acad. Sci. Paris Sér. 3 (Sci. Vie) 315 (1992) 429-435.

[3] Améglio T., Cruiziat P., Béraud S., Alternance tension/pression de la sève dans le xylème chez le noyer pendant l'hiver: conséquences sur la conductance hydraulique des rameaux, C. R. Acad. Sci. Paris Sér. 3 (Sci. Vie) 318 (1995) 351-357.

[4] Améglio T., Cochard H., Picon C., Cohen M., Water relations and hydraulic architecture of peach trees under drought conditions, in: Proc. Fourth Intern. Peach Symposium, Monet R. (Ed.), Acta Hort. 465 (1998) 355-361.

[5] Améglio T., Archer P., Cochen M., Valancogne C., Daudet F.A., Dayau S., Cruiziat P., Significance and limit in the use of predawn leaf water potential for tree irrigation, Plant Soil 207 (1999a) 155-167.

[6] Amégio T., Perrier C., Le Roux X., Mingeau M., Drought effect on water relations and fruit yield in highbush blueberries, Fruits 54 (1999b) 423-430.

[7] Améglio T., Guilliot A., Lacointe A., Alves G., Julien J.L., Petel G., Valentin V., Water relation in winter: Effect on budbreak of walnut tree, in: Viémont J.D., Crabbé J. (Eds.), Dormancy in Plants, CAB International, 2000, pp. 109-120.

[8] André J.P., Heterogeneous, branched, zigzag and circular vessels: unexpected but frequent forms of tracheary element files: description-localization-formation, in: Savidge R.A., Barnett J.R., Napier R. (Eds.), Cell and Molecular Biology of Wood Formation, Experimental Biology Reviews, Bios Scientific Publishers Ltd, Oxford, UK, 2000, pp. 387-395.

[9] André J.P., Une nouvelle vision de l'organisation vasculaire des angiospermes, le moulage histologique, INRA Éditions, 2002.

[10] Assmann E., The principles of forest yield study, Pergamon Press, $1970,560 \mathrm{p}$.

[11] Barthélémy D., Edelin C., Halle F., Canopy Architecture, in: Raghavendra A.S. (Ed.), Physiology of Trees, John Wiley \& Sons, Inc. New York, USA, 1991, pp. 1-20.
[12] Becker P., Tyree M.T., Tsuda M., Hydraulic conductances of angiosperms versus conifers: similar transport sufficiency at the whole-plant level, Tree Physiol. 19 (1999) 445-452.

[13] Becker P., Gribben R.J., Lim C.M., Tapered conduits can buffer hydraulic conductance from path-length effects, Tree Physiol. 20 (2000) 965-967.

[14] Boyer J.S., Water transport, Annu. Rev. Plant Physiol. 36 (1985) 473-516.

[15] Cochard H., Tyree M.T., Xylem dysfunction in Quercus: vessel sizes, tyloses, cavitation and seasonal changes in embolism, Tree Physiol. 6 (1990) 393-407.

[16] Cochard H., Vulnerability of several conifers to air embolism, Tree Physiol. 11 (1992) 73-83.

[17] Cochard H., Cruiziat P., Tyree M.T., Use of positive pressures to establish vulnerability curves. Further support for the air-seeding hypothesis and implications for pressure-volume analysis, Plant Physiol. 100 (1992a) 205-209.

[18] Cochard H., Breda N., Granier A., Aussenac G., Vulnerability to air embolism of three european oak species (Quercus petraea (Matt) Liebl, Q. pubescens Willd, Q. robur L.), Ann. Sci. For. 49 (1992b) 225-233.

[19] Cochard H., L'embolie estivale et hivernale : données actuelles et mécanismes, in: Cruiziat P. (Ed.), L'eau dans la vie de l'arbre, 14-15/04/94, Séminaire du Groupe d'Étude de l'Arbre, Inra-PIAF, Clermont-Ferrand Theix, 1995, pp. 67-97.

[20] Cochard H., Bréda N., Granier A., Whole-tree hydraulic conductance and water losss regulation of Quercus petraea during drought: evidence for stomatal control of embolism? Ann. Sci. For. 53 (1996a) 197-206.

[21] Cochard H., Ridolfi M., Dreyer E., Responses to water stress in an ABA-unresponsive hybrid poplar (Populus koreana $\times$ trichocarpa $\mathrm{cv}$ 'Peace') II: Hydraulic properties and xylem embolism, New Phytol. 134 (1996b) 455-461.

[22] Cochard H., Peiffer M., Le Gall K., Granier A., Developmental control of xylem hydraulic resistances and vulnerability to embolism in Fraxinus excelsior L.: impacts on water relations, J. Exp. Bot. 48 (1997) 655-663.

[23] Cochard H., Granier A., Fonctionnement hydraulique des arbres forestiers, Rev. For. Fr. 2 (1999) 121-134.

[24] Cochard H., Lemoine D., Dreyer E., The effects of acclimation to sunlight on the xylem vulnerability to embolism in Fagus sylvatica L., Plant Cell Environ. 22 (1999) 101-108.

[25] Cochard H., Martin R., Gross P., Bogeat-Triboulot M.B., Temperature effects on hydraulic conductance and water relations of Quercus robur $\mathrm{L}$., J. Exp. Bot. 51 (2000a) 1255-1259.

[26] Cochard H., Bodet C., Améglio T., Cruiziat P., Cryo-Scanning Electron Microscopy Observations of Vessel Content during Transpiration in Walnut Petioles. Facts or Artifacts? Plant Physiol. 124 (2000b) 1-12.

[27] Cochard H., Lemoine D., Améglio T., Granier A., Mechanisms of xylem recovery from winter embolism in Fagus sylvatica, Tree Physiol. 21 (2001) 27-33.

[28] Cochard H., Coll L., Le Roux X., Améglio T., Unraveling the effects of plant hydraulics on stomatal closure during water stress in walnut, Plant Physiol. 128 (2002) 282-290.

[29] Comstock J.P., Sperry J.S., Theoretical considerations of optimal conduit length for water transport in vascular plants, New Phytol. 148 (2000) $195-218$.

[29bis] Comstock J.P., Hydraulic and chemical signalling in the control of stomatal conductance and transpiration, J. Exp. Bot. 53 (2002) 195-200.

[30] Cortes P.M., Sinclair T.R., The role of osmotic potential in spring sap flow of mature sugar maple trees Acer saccharum Marsh., J. Exp. Bot. 36 (1985) 12-24.

[31] Crombie D.S., Hipkins M.F., Milburn J.A., Gas penetration of pit membranes in the xylem of Rhododendron as the cause of acoustically detectable sap cavitation, Aust. J. Plant Physiol. 12 (1985) 445-453.

[32] Cruiziat P., Quelques réflexions concernant l'étude du mécanisme de transfert de l'eau chez les végétaux, Actes du IVème séminaire de l'école de Biologie Théorique, Solignac 4-7/06/1984, Éditions du CNRS, Paris, 1985, pp. 241-251. 
[33] Cruiziat P., Tyree M.H., La montée de la sève dans les arbres, La Recherche 21 (1990) 406-414.

[34] Dainty J., Water relations of plant cells, in: Luttge U., Pitman M.G. (Eds.), Transport in plants, II. Part A. Cells, Encyclopedia of plant physiology, Vol. 2A, Springer-Verlag, Berlin, 1976, pp.12-35.

[35] Davis S.D., Sperry J.S., Hacke G., The relationship bewteen xylem conduit diameter and cavitation caused by freezing, Am. J. Bot. 86 (1999) 1367-1372.

[36] Deleuze C., Pour une dendrométrie fonctionnelle : essai sur l'intégration de connaissances écophysiologiques dans les modèles de production ligneuse, Thèse de Doctorat, Université Claude Bernard, Lyon 1, 1996, 305 p.

[37] Dixon H.H., Joly J., On the ascent of sap, Philos. Trans. R. Soc. London, Ser. Biol. Sci. 186 (1894) 563-576.

[38] Dixon H.H., Transpiration and the ascent of sap in plants, Mac Millan, London, 1914, $216 \mathrm{p}$.

[39] Doussan C., Vercambre G., Pagès L., Water uptake by two constrasting root systems (maize, peach tree): results from a model of hydraulic architecture, Agronomie 19 (1999) 255-263.

[39bis] Engelbrecht B.M.J., Velez V., Tyree M.T., Hydraulic conductance of two co-occuring netropical understory shrubs with different habitat preference, Ann. For. Sci. 57 (2000) 201-208.

[40] Ewers F.W., Zimmermann M.H., The hydraulic architecture of eastern hemlock (Tsuga canadensis), Can. J. Bot. 62 (1984a) 940-946.

[41] Ewers F.W., Zimmermann M.H., The hydraulic architecture of balsam fir (Abies balsamea), Physiol. Plant. 60 (1984b) 453-458.

[42] Ewers F.W., Xylem structure and water conduction in conifer trees, dicot trees, and lianas, IAWA J. 6 (1985) 309-317.

[43] Ewers F.W., Cruiziat P., Measuring water transport and storage, in: Lassoie J.P., Hinckley T.M. (Eds.), Techniques and approaches in forest tree ecophysiology, CRC Press, Boca Raton, Florida, USA, 1991, pp. 91-115.

[44] Ewers F.W., Améglio T., Cochard H., Beaujard F., Martignac M., Vandame M., Bodet C., Cruiziat P., Seasonal variation of xylem pressure in walnut trees: root and stem pressure, Tree Physiol. 21 (2001) 1123-1132.

[45] Farrar J.F., Minchin P.E.H., Carbon partitioning in split-root systems of barley: relation to metabolism, J. Exp. Bot. 42 (1991) 1261-1269.

[46] Fujii T., Hatano Y., The LDPE resin-casting method applied to vessel characterisation, IAWA J. 21 (2000) 347-359.

[47] Gradmann H., Untersuchungen über die Wasserverhältnisse des Bodens als Grundlage des Pflanzenwachstums. I., Jahrb. wiss. Bot. 69 (1928) $1-100$.

[48] Granier A., Evaluation of transpiration in Douglas fir stand by means of sap flow measurements, Tree Physiol. 3 (1987) 309-320.

[49] Granier A., Anfodillo T., Sabatti M., Cochard H., Dreyer E., Tomasi M., Valentini R., Bréda N., Axial and radial water flow in the trunk of oak trees: a quantitative and qualitative analysis, Tree Physiol. 14 (1994) 1383-1396.

[50] Hacke U.G., Sauter J.J., Vulnerability of xylem to embolism in relation to leaf water potential and stomatal conductance in Fagus sylvaticaf. purpurea and Populus balsamifera, J. Exp. Bot. 46 (1995) 1177-1183.

[51] Hacke U.G., Sperry J.S., Pittermann J., Drought experience and cavitation resistance in six shrubs from the Great Basin Utah, Basic Appl. Ecol. 1 (2000a) 31-41.

[52] Hacke U.G., Sperry J.S., Ewers B.E., Ellsworth D.S., Schäfer K.V.R., Oren R., Influence of soil porosity on water use in Pinus taeda, Oecologia 124 (2000b) 495-505.

[53] Hacke U.G., Sperry J.S., Pockmann W.T., Davis S.D., Mc Culloh K.A., Trends in wood density and structure are linked to prevention of xylem implosion by negative pressure, Oecologia 126 (2001) 457-461.

[54] Hallé F., Oldeman R.A.A., Tomlinson P.B., Tropical trees and forests. An architectural analysis, Springer-Verlag, Berlin, DEU, 1978, 441 p.

[55] Holbrook N.M., Zwieniecki M.A., Embolism repair and xylem tension. Do we need a miracle? Plant Physiol. 120 (1999) 7-10.

[56] Huber B., Weitere quantitative Untersuchungen über des Wasserleitung System der Pflanzen, Jahrb. wiss. Bot. 67 (1928) 877-959.
[57] Huber B., Die physiologische Bedeutung der Ring- und Zerstreutporigkeit, Ber. Dtsch. Bot. Ges. 53 (1935) 711-719.

[58] Jarvis P.G., Water transfer in plants, in: De Vries A., Afgan N.H. (Eds.), Heat and mass transfer in the biosphere, Part I. Transfer processes in the plant environment, Seminar, International Centre for Heat and Mass Transfer, Dubrovnik, (YUG), 1974, John Wiley Scripta Book Co. Washington DC, USA, 1975, pp. 369-394.

[59] Johnson L.P.V., Physiological studies on sap flow in the sugar maple Acer saccharum Marsh, Can. J. Res. C. Bot. Sci. 23 (1945) 192-197.

[60] Johnson R.W., Tyree M.T., Dixon M.A., A requirement for sucrose in xylem sap flow from dormant maple trees, Plant Physiol. 84 (1987) 495-500.

[61] Jones H.G., Sutherland R.A., Stomatal control of xylem embolism, Plant Cell Environ. 18 (1991) 189-196.

[62] Kirkham M.B., Physical model of water in a split-root system, Plant Soil 75 (1983) 153-168.

[63] Kramer P.J., Boyer J., Water relations of plants and soils, Academic Press, New York, USA, 1995, 495 p.

[64] Langan S.J., Ewers F.W., Davis S.D., Xylem dysfunction caused by water stress and freezing in two species of co-occurring chaparral shrubs, Plant Cell Environ. 20 (1997) 425-437.

[65] Lemoine D., Granier A., Cochard H., Mechanism of freeze-induced embolim in Fagus sylvatica L., Trees 13 (1999) 206-210.

[66] Lewis A.M., Harnden V.D., Tyree M.T., Collapse of water-stress emboli in the tracheids of Thuja occidentalis L., Plant Physiol. 106 (1994) 1639-1646.

[67] Linton M.J., Nobel P.S., Loss of water transport capacity due to xylem cavitation in roots of two CAM succulents, Am. J. Bot. 11 (1999) 1533-1543.

[68] Lu P., Écophysiologie et réaction à la sécheresse de trois espèces de conifères (Abies alba Miller, Picea abies (L) Karsten et Pinus sylvestris L.) : effet de l'âge, Thèse de Doctorat, Université de Nancy I, 1992, 116 p.

[69] Lu P., Biron P., Granier A., Cochard H., Water relations of adult Norway spruce (Picea abies (L) Karst) under soil drought in the Vosges mountains: Whole-tree hydraulic conductance, xylem embolism and water loss regulation, Ann. Sci. For. 53 (1996) 113-121.

[70] Mackay J.F.G., Weatherley P.E., The effects of transverse cuts through the stems of transpiring woody plants on water transport and stress in the leaves, J. Exp. Bot. 24 (1973) 15-28.

[71] Mäkelä A., Implications of the pipe model theory on dry matter partitioning and heigth in individual trees, J. Theor. Biol. 33 (1986) 103-120.

[72] Mäkelä A., Modeling structural-functional relationships in wholetree growth: resource allocation, in: Dixon R.K., Meldahl R.S., Ruark G.A., Warren W.G. (Eds.), Process Modeling of Forest Growth responses to environmental stress, Timber Press, Portland, Oregon, USA, 1990, pp. 81-95.

[73] Marvin J.W., Greene M.T., Temperature induced sap flow in excised stems of Acer, Plant Physiol. 26 (1951) 565-580.

[74] Marvin J.W., The physiology of maple sap flow, in: Thimann K.V. (Ed.), The Physiology of Forest Trees, Ronald Press, New York, USA, 1958, pp. 95-124.

[75] Marvin J.W., Morselli M.F., Laing F.M., Rapid low temperature hydrolysis of starch to sugars in maple stems and maple tissue cultures, Cryobiology 8 (1967) 339-351.

[76] Martre P., Cochard H., Durand J.L., Hydraulic architecture and water flow in growing grass tillers (Festuca arundinacaea Schreb.), Plant Cell Environ. 24 (2001a) 65-76.

[77] Martre P., North G.B., Nobel P.S., Hydraulic conductance and mercury-sensitive water transport for roots of Opuntia acanthocarpa in relation to soil drying and rewetting, Plant Physiol. 126 (2001b) 352-362.

[78] Mencuccini M., Comstock J., Vulnerability to cavitation in populations of two desert species, Hymenoclea salsola and Ambrosia dumosa, from different climatic regions, J. Exp. Bot. 48 (1997) 1323-1334.

[79] Milburn J.A., The conduction of sap. I. Water conduction and cavitation in water stressed leaves, Planta 65 (1966) 34-42.

[80] Milburn J.A., O'Malley P.E.R., Freeze-induced sap absorption in Acer pseudoplatanus: a possible mechanism, Can. J. Bot. 62 (1984) 2101-2106. 
[81] Milburn J.A., Cavitation and embolisms in xylem conduits, in: Raghavendra A.S. (Ed.), Physiology of Trees, John Wiley \& Sons, Inc., New York, USA, 1991, pp. 163-174.

[82] Milburn J.A., Sap ascent in vascular plants: challengers to the cohesion theory ignore the significance of immature xylem and recycling of Münch water, Ann. Bot.-London 78 (1996) 399-407.

[83] Nadezhdina N., Cermak J., Responses of sap flow rate along tree stem and coarse root radii to changes of water supply, in: Stokes A. (Ed.), The supporting roots of trees and woody plants: form, function and physiology, International meeting, 20-24/07/1998, Bordeaux, France, Partly reprinted from Plant Soil 217 (1999) pp. 227-238.

[83 bis] Nardini A., Salleo S., Tyree M.T., Influence of ectomycrrhizas formed by Tuber melanosporum Vitt. on hydraulic conductance and water relations of Quercus ilex L. seedlings, Ann. For. Sci. 57 (2000) 305-312.

[84] Nikinmaa E., Analyses of the growth of scots pine: matching structure with function, D. sc. thesis, Acta For. Fenn. 235, 1992, 68 p.

[85] Nobel P.S., Physicochemical and environmental plant physiology, 2nd ed., Academic Press, San Diego, CA, USA, 1999, 474 p.

[86] North G.B., Nobel P.S., Changes in hydraulic conductivity and anatomy caused by drying and rewetting roots of Agave deserti (Agavaceae), Am. J. Bot. 78 (1991) 906-915.

[87] O'Malley P.E.R., Xylem sap flow and pressurization in Acer pseudoplatanus L., Ph.D. thesis, Dept of Botany, University of Glasgow, Scotland, UK, 1979, 149 p.

[88] O'Malley P.E.R., Milburn J.A., Freeze-induced fluctuations in xylem sap pressure in Acer pseudoplatanus, Can. J. Bot. 61 (1983) 3100-3106.

[89] Pallardy S.G., Hydraulic architecture and conductivity: an overview, in: Kreeb K.H., Richter H., Hinckley T.M. (Eds.), Structural and functional responses to environmental stresses: water shortage, 14 international botanical Congress, Berlin, DEU, 1987/07/24-08/01, SPB Academic Publishing, The Hague, NLD, 1989, pp. 3-19.

[90] Patiño S., Tyree M.T., Herre E.A., Comparison of hydraulic architecture of woody plants of differing phylogeny and growth form with special reference to free-standing and hemi-epiphytic Ficus species from Panama, New Phytol. 129 (1995) 125-134.

[91] Perttunen J., Sievänen R., Nikinmaa H., Salminen H., Saarenmaa H., Väkevä J., LIGNUM: A tree model based on simple structural units, Ann. Bot.-London, 77 (1996) 87-98.

[92] Pickard W.F., The ascent of sap in plants, Prog. Biophys. Mol. Biol. 37 (1981) 181-229.

[93] Pickard W.F., How might a tracheary element which is embolized by day be healed by night, J. theor. Biol. 141 (1989) 259-279.

[94] Pockman W.T., Sperry J.S., Freezing-induced xylem cavitation and the northern limit of Larrea tridentata, Oecologia 109 (1997) 19-27.

[95] Pockman W.T., Sperry J.S., Vulnerability to xylem cavitation and the distribution of Sorona Desert Vegetation, Am. J. Bot. 87 (2000) 1287-1299.

[96] Ritman K.T., Milburn J.A., Acoustic emissions from plants. Ultrasonic and audible compared, J. Exp. Bot. 39 (1988) 1237-1248.

[97] Roach W.A., Plant injection as a physiological method, Ann. Bot. 3 (1939) 155-226.

[98] Rood S.B., Patiño S., Coombs K., Tyree M., Branch sacrifice: cavitation-associated drought adaptation of riparian cottonwoods, Trees 14 (2000) $248-257$.

[99] Ryan M.G., Yoder B., Hydraulic Limits to Tree Height and Tree Growth, Bioscience 47 (1997) 235-242.

[100] Salleo S., Nardini A., Pitt F., Lo Gullo M., Xylem cavitation and hydraulic control of stomatal conductance in Laurel (Laurus nobilis L.), Plant Cell Environ. 23 (2000) 71-79.

[101] Sauter J.J., Maple, McGraw-Hill yearbook of science and technology, McGraw-Hill Publ. New York, USA, 1974, pp. 280-281.

[102] Shinozaki K., Yoda K., Hozumi K., Kira T., A quantitative analysis of plant form. The pipe model theory. I. Basic analyses, Jap. J. Ecol. 14 (1964a) 97-132.

[103] Shinozaki K., Yoda K., Hozumi K., Kira T., A quantitative analysis of plant form. The pipe model theory. II. Further evidence of the theory and its implications in forest ecology, Jap. J. Ecol. 14 (1964b) 133-139.
[104] Sperry J.S., Relationship of xylem embolism to xylem pressure potential, stomatal closure, and shoot morphology in the palm Rhapis excelsa, Plant Physiol. 80 (1986) 110-116.

[105] Sperry J.S., Holbrook N.M., Zimmermann M.H., Tyree M.T., Spring filling of xylem vessels in wild grapevine, Plant Physiol. 83 (1987) 414-417.

[106] Sperry J.S., Tyree M.T., Mechanism of water stress-induced xylem embolism, Plant Physiol. 88 (1988) 581-587.

[107] Sperry J.S., Donnelly J.R., Tyree M.T., A method for measuring hydraulic conductivity and embolism in xylem, Plant Cell Environ. 11 (1988a) $35-40$.

[108] Sperry J.S., Donnelly J.R., Tyree M.T., Seasonal occurrence of xylem embolism in sugar maple (Acer saccharum), Am. J. Bot. 75 (1988b) $1212-1218$.

[109] Sperry J.S., Tyree M.T., Water-stress-induced xylem embolism in three species of conifers, Plant Cell Environ. 13 (1990) 427-436.

[110] Sperry J.S., Sullivan J.E.M., Xylem embolism in response to freezethaw cycles and water stress in ring-porous, diffuse-porous, and conifer species, Plant Physiol. 100 (1992) 605-613.

[111] Sperry J.S., Saliendra N.Z., Intra- and inter-plant variation in xylem cavitation in Betula occidentalis, Plant Cell Environ. 17 (1994) 1233-1241.

[112] Sperry J.S., Nichols K.L., Sullivan J.E.M., Eastlack S.E., Xylem embolism in ring-porous, diffuse-porous, and coniferous trees of northern Utah and interior Alaska, Ecology 75 (1994) 1736-1752.

[113] Sperry J.S., Saliendra N.Z., Pockman W.T., Cochard H., Cruiziat P., Davis S.D., Ewers F.W., Tyree M.T., New evidence for large negative xylem pressures and their measurement by the pressure chamber method, Plant Cell Environ. 19 (1996) 427-436.

[114] Sperry J.S., Adler F.R., Campbell G.S., Comstock J.C., Limitation of plant water use by rhizosphere and xylem conductances: results from a model, Plant Cell Environ. 21 (1998) 347-359.

[115] Sperry J.S., Hydraulic constraints on plant gas exchange, Agric. For. Meteorol. 104 (2000) 13-23.

[116] Steudle E., Methods for studying water relations of plant cells and tissues, in: Hashimoto Y., Nonami H., Kramer P.J., Strain B.R. (Eds.), Measurement techniques in plant sciences, Academic Press, San Diego, CA, USA, 1990, pp. 113-150.

[117] Steudle E., Peterson C.A., How does water get through roots?, J. Exp. Bot. 49 (1998) 775-788.

[118] Steudle E., The cohesion-tension theory mechanism and the acquisition of water by plant roots, Annu. Rev. Plant Physiol. Plant Mol. Biol. 52 (2001) 847-875.

[119] Stevens C.L., Eggert R.L., Observations on the causes of flow of sap in red maple, Plant Physiol. 20 (1945) 636-648.

[120] Tardieu F., Zhang J., Katerji N., Bethenod O., Palmer S., Davies W.J., Xylem ABA controls the stomatal conductance of field-grown maize subjected to soil compaction or soil drying, Plant Cell Environ. 15 (1992) 193-197.

[121] Tyree M.T., Jarvis P.G., Water in tissues and cells, in: Lange O.L., Nobel P.S., Osmond C.B., Ziegler H. (Eds.), Physiological plant ecology II. Water relations and carbon assimilation, Encyclopedia of plant physiology, Vol. 12B, Springer-Verlag, New York, USA, 1982, pp. 35-77.

[122] Tyree M.T., Maple sap uptake, exudation and pressure changes correlated with freezing exotherms and thawing endotherms, Plant Physiol. 73 (1983) 277-285.

[123] Tyree M.T., A dynamic model for water flow in a single tree: evidence that models must account for hydraulic architecture, Tree Physiol. 4 (1988) 195-217.

[124] Tyree M.T., Sperry J.S., Do woody plants operate near the point of catastrophic xylem dysfunction caused by dynamic water stress? Answers from a model, Plant Physiol. 88 (1988) 574-580.

[125] Tyree M.T., Sperry J.S., Vulnerability of xylem to cavitation and embolism, Annu. Rev. Plant Physiol. Plant Mol. Biol. 40 (1989a) 19-38.

[126] Tyree M.T., Sperry J.S., Characterization and propagation of acoustic emission signals in woody plants: towards an improved acoustic emission counter, Plant Cell Environ. 12 (1989b) 371-382. 
[127] Tyree M.T., Ewers F.W., The hydraulic architecture of trees and other woody plants, New Phytol. 119 (1991) 345-360.

[128] Tyree M.T., Synderman D.A., Wilmot T.R., Machado J.L., Water relations and hydraulic architecture of a tropical tree (Schefflera morototoni). Data, models and a comparison with two temperate species (Acer saccharum and Thuja occidentalis), Plant Physiol. 96 (1991) 1105-1113.

[129] Tyree M.T., Yang S.C., Hydraulic conductivity recovery versus water pressure in xylem of Acer saccharum, Plant Physiol. 100 (1992) 669-676.

[130] Tyree M., Alexander J.D., Hydraulic conductivity of branch junctions in three temperate tree species, Trees 7 (1993) 156-159.

[131] Tyree M.T., Cochard H., Cruiziat P., Sinclair B., Ameglio T., Drought-induced leaf shedding in walnut. Evidence for vulnerability segmentation, Plant Cell Environ. 16 (1993a) 879-882.

[132] Tyree M.T., Sinclair B., Lu P., Granier A., Whole shoot hydraulic resistance in Quercus species measured with a new high-pressure flowmeter, Ann. Sci. for. 50 (1993b) 417-423.

[133] Tyree M.T., Davis S.D., Cochard H., Biophysical perspectives of xylem evolution: is there a tradeoff of hydraulic efficiency for vulnerability to dysfunction? IAWA J. 15 (1994) 335-346.

[134] Tyree M.T., Cochard H., Summer and winter embolism in oak: impact on water relations, Ann. Sci. for. 53 (1996) 173-180.

[135] Tyree M.T., The cohesion-tension theory of sap ascent: current controversies, J. Exp. Bot. 48 (1997) 1753-1765.

[136] Tyree M.T., Velez V., Dalling J.W., Growth dynamics of root and shoot hydraulic conductance in seedlings of five neotropical tree species: scaling to show possible adaptations light regimes, Oecologia 114 (1998) 293-298.

[137] Tyree M.T., Water relations and hydraulic architecture, in: Pugnaire F.I., Valladares F. (Eds.), Handbook of Functional Plant Ecology, Marcel Dekker Inc., New York, USA, 1999, pp. 221-268.

[138] Tyree M.T., Sobrado M.A., Stratton L.J., Becker P., Diversity of hydraulic conductances in leaves of temperate and tropical species: possible causes and consequences, J. Trop. For. Sci. 11 (1999a) 47-60.

[139] Tyree M.T., Salleo S., Nardini A., Lo Gullo M.A., Mosca R., Refilling of embolized vessels in young stems of laurel. Do we need a new paradigm? Plant Physiol. 120 (1999b) 11-21.

[140] Valancogne C., Nasr Z., A heat balance method for measuring sap flow in small trees, in: Borghetti M., Grace J., Raschi A. (Eds.), Water transport in plants under stress, Cambridge University Press, Cambridge, UK, 1991, pp. 166-173.

[141] Valentine H.T., A carbon balance model of stand growth: a derivation employing pipe-model theory and the self-thinning rule, Ann. Bot.-London 62 (1988) 389-396.
[142] Valentine H.T., Gregoire T.G., Burkhart H.E., Hollinger D.Y., A stand level model of carbon allocation and growth, calibrated for loblolly pines, Can. J. For. Res. 27 (1997) 579-585.

[143] Van Den Honert T.H., Water transport in plants as a catenary process, in: Interaction of water and porous materials, Discuss. Faraday Soc. 3 (1948) 146-153.

[144] Van Ieperen W., van Meeteren U., van Gelder H., Fluid composition influences hydraulic conductance of xylem conduits, J. Exp. Bot. 51 (2000) 769-776.

[145] Waisel Y., Liphschitz N., Kuller Z., Patterns of water movement in trees and shrubs, Ecology 53 (1972) 520-523.

[146] Wang J., Ives N.E., Lechowicz M.J., The relation of foliar phenology to xylem embolism in trees, Funct. Ecol. 6 (1992) 469-475.

[147] West G.B., Brown J.H., Enquist B.J., A general model for the structure and allometry of plant vascular systems, Nature 400 (1999) 664-667.

[148] Wiegand K.M., Pressure and flow of sap in the maple, Am. Nat. 40 (1906) 409-453.

[149] Yang S., Tyree M.T., A theoretical model of hydraulic conductivity recovery from embolism with comparison to experimental data on Acer saccharum, Plant Cell Environ. 15 (1992) 633-643.

[150] Yang S., Tyree M.T., Hydraulic architecture of Acer saccharum and A. rubrum. Comparison of branches to whole trees and the contribution of leaves to hydraulic resistance, J. Exp. Bot. 45 (1994) 179-186.

[151] Zhu X.B., Cox R.M., Arp P.A., Effects of xylem cavitation and freezing injury on dieback of yellow birch (Betula alleghaniensis) in relation to a simulated winter thaw, Tree Physiol. 20 (2000) 541-547.

[152] Zimmermann M.H., Brown C.L., Trees structure and function, Springer-Verlag, New York, USA, 1977, 336 p.

[153] Zimmermann M.H., Hydraulic architecture of some diffuse-porous trees, Can. J. Bot. 56 (1978) 2286-2295.

[154] Zimmermann M.H., Xylem structure and the ascent of sap, SpringerVerlag, New York, USA, 1983, 143 p. A new edition, completed by M. Tyree, should appear in 2002.

[155] Zwieniecki M.A., Holbrook N.M., Diurnal variation in xylem hydraulic conductivity in white ash (Fraxinus americana L.), red maple (Acer rubrum L.) and red spruce (Picea rubens Sarg.), Plant Cell Environ. 18 (1998) 1173-1180.

[156] Zwieniecki M.A., Melcher P.J., Holbrook N.M., Hydrogel control of xylem hydraulic resistance in plants, Science 291 (2001) 1059-1062.

To access this journal online: www.edpsciences.org 